\title{
A Numerical Study of Local Circulation as Influenced by Clouds
}

\author{
by \\ Koichi Shirasaki \\ Meteorological Research Institute, Tsukuba, Ibaraki 305, Japan \\ (Received Dec. 9, 1985 ; Revised July 8, 1986)
}

\begin{abstract}
A two-dimensional numerical model which contains mountain and sea surface has been developed mainly to study the influence of cumulus convection and radiation on the local circulation. Numerical experiments were carried out for four cases.

Case 1 is the basic one which contains only the computation of net radiation on the ground surface to predict ground surface temperature. Cooling or warming due to radiation in the atmosphere and the effects of cloud are not taken into consideration.

Net radiative fluxes at each level including the influence of cloud are estimated in Case 2 , but the process of cumulus convection is not included in this case.

Case 3 is the same as Case 1 but the cumulus convection can be treated.

Net radiation at each level containing cloud effects and cumulus convection are taken into consideration in Case 4.

The experimental results show that clouds exert great influence on ground surface temperatures and the local circulation itself through the processes of condensation and radiation.

The computation of net radiation in the atmosphere is very important in simulating the surface inversion layer and the thin downslope wind on the slope at nighttime. The formation of clouds in the daytime suppresses the circulation due to rapid depression of net solar radiation on the ground. However, it enhances vertical velocity over the mountain through the cumulus convection. In this case, the anti-slope wind seems to be weakened. Namely clouds have effects which oppose each other on the circulation.

The high temperature in a cloud as compared with its environs and lower one at the upper adjacent layer can be simulated if both effects are taken into consideration.

In addition, clouds delay the onset of downslope wind if they remain after sunset.
\end{abstract}

\section{Introduction}

The method of predicting the ground surface temperature may be one of the most important problems concering numerical simulations of local circulations.

Many investigators have employed a surface energy budget to predict the surface soil temperature after Magata (1965), and obtained satisfactory results on local wind systems and temperature fields by comparison with observational data.

For example, Yamada (1981) simulated the nocturnal drainage flow in parts of the California Geysers area. He showed that the effects of canopy flow should be taken into account in the simulation of the flow in the surface thin layer.

Segal et al. (1982) obtained remarkable success in simulating the local climate pattern associated with typical July stagnant synoptic meteorological conditions in northern Israel. Especially their numerical results on air temperature near the ground surface agreed well with observed data.

Ookouchi and Wakata (1984) also studied 
influences of complex mountanious features of the northern region of Kyushu Island on the sea -land breeze circulations, and accurately reproduced the surface wind system.

It is a well-known fact, however, that we observe cumulus cloud associated with the sea -land breeze front or the topographical ascending current in mountanious areas. In this case the existence of clouds may serve to strengthen vertical velocity and circulation. But, on the other hand, it is thinkable that gathering clouds intercept sun-beams and weaken the circulation through the heat balance on the ground surface, and that the existence of clouds in daytime may have some effects upon the circulation in the nighttime.

Numerical experiment, at any rate, must be done about the effects of clouds on the lower atmosphere and ground surface if we want to investigate the actual phenomena of local circulations.

The intent of the present basic study is to test the effects of clouds and clarify the importance of the interaction between clouds and radiative processes in the local circulation.

Our numerical model is fundamentally the same as the local circulation model developed by Kikuchi et al. (1981). Improvements were made by Kimura and Arakawa (1983). They took into account the effects of net radiation on the ground surface in a cloudless model to predict the ground surface temperature by the force restore method (Bhumralker, 1975 and Deardorff, 1978). We want to test the effects of condensation and radiative processes on the circulation by comparison with their model.

In this paper, numerical experiments are performed for four cases by a two-dimensional model :

Case 1 is the basic experiment which contains the computation of net radiation on the earth's surface to predict surface temperature.

Clouds due to cumulus convection and heating due to radiative process including the influence of clouds are not taken into consideration.

Net radiative fluxes at each lavel including cloud effects are estimated in Case 2, but the process of cumulus convection is not included in this case.
Case 3 is the same as case 1 but the cumulus convection is treated.

In addition to radiative fluxes at each level containing cloud, cumulus convection is taken into consideration in Case 4.

In sections 2 and 3 , model aspects and parameterization schemes of physical processes are described. In section 4 the computational results are presented, and the conclusion will follow in section 5 .

\section{Model aspect}

The numerical model is fundamentally the same as the local circulation model developed by Kikuchi et al (1981). Improvements were made by Kimura and Arakawa (1983) and Kimura (1983, 1984). They discussed the nocturnal low level jet over the Kanto Plain using this new model. Kimura (1983) also carried out the numerical simulation of sea -land breeze and photochemical air pollution.

So only the basic equations and improvements in Kimura and Arakawa (1983) will be given.

\section{(1) Model atmosphere}

The model considered is a two-dimensional one and contains sea-land distribution and mountain following the purpose of this study.

The area width is $150 \mathrm{~km}$ from east to west and the sea surface distribution is $25 \mathrm{~km}$ in breadth on the east side and the monutain is located at the central region of land, about 80 $\mathrm{km}$ in width and $1000 \mathrm{~m}$ in height as shown in Fig 1. The grid interval in the horizontal direction is chosen to be $5 \mathrm{~km}$. The vertical thickness of the model atmosphere is $6000 \mathrm{~m}$, divided into 15 layers with smaller intervals for the lower layers.

As the characteristics of our model, the upper boundary of the top layer $\left(h_{m}(x, y, t)\right)$ was assumed to be material surface, and the law of mass conservation is guaranteed in the model atmosphere.

Above the top layer, there is the free atmosphere where potential temperature is assumed to be somewhat higher than that of the top layer and constant in space and time. 


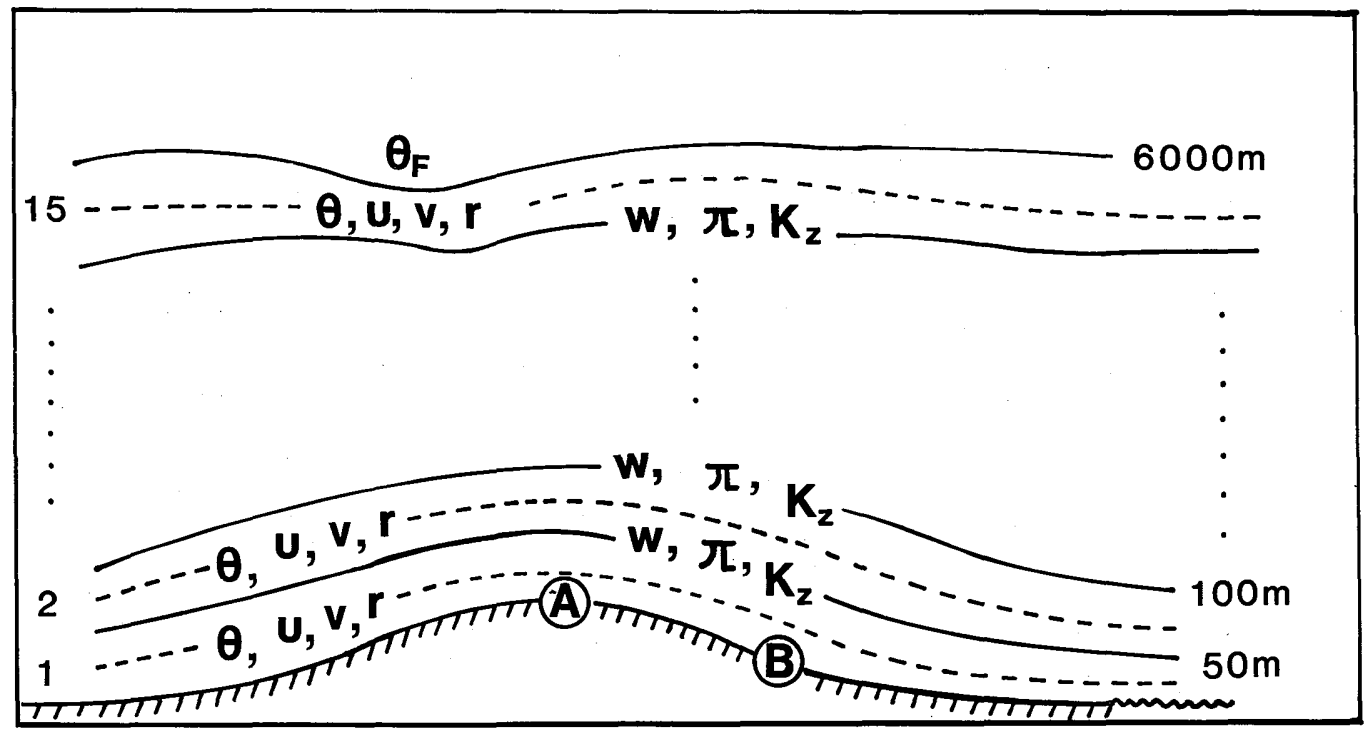

West

point A:1000m point B:200m

East

Fig. 1 Vertical structure of the model atmosphere

(2) Basic equations

The equations are expressed by the Boussinesq hydrostatic systems and are written in a terrain-following coordinate system.

Equation of motion :

$$
\begin{aligned}
& \frac{\partial h u}{\partial t}+\frac{\partial h u u}{\partial x}+\frac{\partial h u w^{*}}{\partial z^{*}}=f h v \\
& -h \Theta \frac{\partial \pi^{\prime}}{\partial x}+g h \frac{\theta^{\prime}}{\Theta} \frac{z_{T}-z^{*}}{z_{T}} \frac{\partial z_{G}}{\partial x} \\
& +\frac{\partial}{\partial x}\left(h K_{H} \frac{\partial u}{\partial x}\right)+\frac{z_{T}^{2}}{h} \frac{\partial}{\partial z^{*}}\left(K_{m} \frac{\partial u}{\partial z^{*}}\right) \\
& \frac{\partial h v}{\partial t}+\frac{\partial h u v}{\partial x}+\frac{\partial h v w^{*}}{\partial z^{*}}=-f h u \\
& -h \Theta \frac{\partial \pi^{\prime}}{\partial y}+\frac{\partial}{\partial x}\left(h K_{H} \frac{\partial v}{\partial x}\right) \\
& +\frac{z_{T}^{2}}{h} \frac{\partial}{\partial z^{*}}\left(K_{m} \frac{\partial v}{\partial z^{*}}\right)
\end{aligned}
$$

Equations of thermodynamics :

$$
\begin{aligned}
& \frac{\partial h \theta^{\prime}}{\partial t}+\frac{\partial h \theta^{\prime} u}{\partial x}+\frac{\partial h \theta^{\prime} w^{*}}{\partial z^{*}}=\frac{\partial}{\partial x}\left(h K_{H} \frac{\partial \theta}{\partial x}\right) \\
& +\frac{z_{T}^{2}}{h} \frac{\partial}{\partial z^{*}}\left(K_{\theta} \frac{\partial \theta^{\prime}}{\partial z^{*}}\right)+E .
\end{aligned}
$$

Continuity equation and hydrostatic equation:

$$
\frac{\partial h u}{\partial x}+\frac{\partial h w^{*}}{\partial z^{*}}=0
$$

$$
\frac{\partial \pi^{\prime}}{\partial z^{*}}=\frac{h}{z_{T}} \frac{g}{\Theta^{2}} \theta^{\prime}
$$

Equation of mixing ratio :

$$
\begin{aligned}
& \frac{\partial h r}{\partial t}+\frac{\partial h r u}{\partial x}+\frac{\partial h r w^{*}}{\partial z^{*}}=\frac{\partial}{\partial x}\left(h K_{H} \frac{\partial r}{\partial x}\right) \\
& +\frac{z_{T}^{2}}{h} \frac{\partial}{\partial z^{*}}\left(K_{r} \frac{\partial r}{\partial z^{*}}\right)-Q,
\end{aligned}
$$

where $z^{*}$ is the terrain-following vertical coordinate defined as

$$
z^{*}=z_{T} \frac{z-z_{G}}{h}, h=z_{T}-z_{G},
$$

in which $z_{T}$ and $z_{G}$ are the levels of the top and the ground surface of the model atmosphere, respectively ; $w^{*}$ is the vertical $z^{*}$-velocity, $\mathrm{E}$ and $Q$ are the rate of diabatic heating due to condensation and radiation; the other symbols are as usual and shown in Appendix.

(3) Boundary and initial conditions

A. Boundary condtions

(i) at the surface $\left(z^{*}=0\right)$

$$
u=v=w^{*}=0
$$

and potential temperature deviation $\theta^{\prime}$ is determined by the heat balance equation as shown with the mixing ratio $r$ in the next section. 
(ii) at the top

$$
\begin{aligned}
& w^{*}=0 \\
& \pi^{\prime}=\overline{\pi^{\prime}}+g \frac{\theta_{F}-\theta}{\Theta}\left(h_{m}-\bar{h}_{m}\right)+F \frac{\partial h_{m}}{\partial t},
\end{aligned}
$$

where $h_{m}$ and $\bar{h}_{m}$ are the depth of the top layer and its initial value, respectively, and the last term on the right-hand side is the additional term to suppress the computational mode appearing in $h_{m}$. This idea was proposed by Kimura (1984).

Taking some value for $F$, he succeeded in dumping the gravitational mode with short wavelength. For particulars, see to Kimura (1984).

(iii) at the lateral boundary

$$
\frac{\partial}{\partial x}\left(u, v, \theta^{\prime}, r\right)=0 \text {. }
$$

\section{B. initial conditions}

The computation started at 18:00 LST of summer solstice. Following intial values are assumed.

$$
\begin{aligned}
& u=v=0, \\
& \theta=\theta_{\text {sea }}+\Gamma_{z}, \\
& \text { relative humidity }=70 \%, \\
& \theta_{g}=\left(\theta_{g}\right)_{0}=\theta_{\text {sea }}+\Gamma_{z},
\end{aligned}
$$

where $\Gamma=0.33^{\circ} \mathrm{C} / 100 \mathrm{~m}, \theta_{\text {sea }}=298.0^{\circ} \mathrm{K}$ and $\left(\theta_{g}\right)_{0}$ is the average surface soil temperature assumed to be constant.

Time integration is performed by the Euler backward scheme except for the vertical diffusion terms by the trapezoidal implicit scheme. The time increment of integration is 60 seconds.

\section{Parameterizations of physical processes.}

\section{(1) Surface energy balance}

Kimura and Arakawa (1983) adopted the force restore method to predict the ground surface temperature $T_{g}$. The method will be explained briefly in order. The prognostic equation of $T_{g}$ is written as follows :

$$
\begin{aligned}
\frac{\partial T_{g}}{\partial t}= & \frac{1}{c_{1}}(S+R-H-l E) \\
& -\frac{1}{C_{2}}\left[\mathrm{~T}_{g}-\left(T_{g}\right)_{0}\right],
\end{aligned}
$$

where $\mathrm{S}, \mathrm{R}, \mathrm{H}, \mathrm{IE}$ are the total solar radiation absorbed on the surface, $R$ the net longwave radiation, $H$ the upward sensible heat flux, and
IE the upward latent heat flux.

$\left(T_{g}\right)_{0}$ is the average surface temperature. Coefficients $C_{1}, C_{2}$ are given as:

$$
C_{1}=\sqrt{\frac{k c}{2 \omega}}, \quad C_{2}=\frac{1}{\omega},
$$

where $\omega=2 \pi / d a y, k$ and $c$ are the heat conductivity and the heat capacity of the soil, respectively.

These are calulated after Katayama (1978) :

$$
\begin{aligned}
& C=0.386+0.15 w^{\prime}\left(\mathrm{cal} \mathrm{cm}^{-3}{ }^{\circ} \mathrm{K}^{-1}\right), \\
& k=0.002+0.002 w^{\prime}\left(\mathrm{cal} \mathrm{cm}^{-1} \mathrm{sec}^{-1}{ }^{\circ} \mathrm{K}^{-1}\right),
\end{aligned}
$$

and $w^{\prime}$ is the wetness of the soil.

The sea surface temperature cannot be exactly predicoed by eq. (7) due to the radiative flux into the sea. But the diurnal variation of the sea surface temperature is so small that Kimura and Arakawa (1983) used eq. (7) assuming that $c$ is $1.0 \mathrm{cal} /\left(\mathrm{crn}^{3 \circ} \mathrm{K}\right)$ and $k$ is 10 $\mathrm{cal} /\left(\mathrm{cm} \mathrm{sec}^{\circ} \mathrm{K}\right)$.

In connection with the latent heat flux in eq. (7), we must decide the value of the mixing ratio at the ground surface. This problem is very important not only for the general circulation model or climatic change but also for local circulation.

Following Katayama (1978), $r_{0}$, the mixing ratio on the ground surface, is assumed as:

$$
r_{1}-r_{0}=\beta\left\{r_{0}-\left(r_{0}\right)_{s}\right\},
$$

where $r_{1}$ and $\left(r_{0}\right)_{s}$ are the mixing ratio at the lowest level, and the saturated mixing ratio on the surface, respectively. $\beta$ is evaporation efficiency, which is given as

$$
\beta=\min \left(1.0,2 w^{\prime}\right)
$$

\section{(2) Eddy parameterization}

The representation of the vertical diffusion processes is reduced to the calculation of the vertical exchange coefficients.

There are many formulae concerning them but we adopted this time the turbulent closure level 2 scheme of Mellor and Yamada (1974). The excellent characteristic of their method is that they calculate the vertical exchange coefficients from the local Richardson number.

The vertical exchange coefficients of momentum and heat and mixing ratio are expressed as :

$$
K_{m}=l^{2}\left|\frac{\partial U}{\partial z^{*}}\right| S_{M},
$$




$$
K_{\theta}=K r=l^{2}\left|\frac{\partial U}{\partial z^{*}}\right| S_{H},
$$

where $l$ is a characteristic length of turbulence and $S_{M}, S_{H}$ are functions of flux Richardson number $\left(R_{f}\right)$ and further formulations are omitted.

$$
\begin{aligned}
R_{f}= & 0.725\left[R_{i}+0.186-\left({R_{i}}^{2}+0.316 R_{i}\right.\right. \\
& \left.+0.0346)^{\frac{1}{2}}\right\rfloor
\end{aligned}
$$

where $R_{i}$ is the gradient Richardson number,

$$
R_{i}=\frac{g}{\Theta_{e}} \frac{\frac{\partial \theta_{e}}{\partial z^{*}}}{\left(\frac{\partial U}{\partial z^{*}}\right)^{2}}
$$

and $\theta_{e}$, equivalent potential temperature :

$$
\theta_{e}=\theta \exp \left(L r / c_{p} \mathrm{~T}\right)
$$

Formulation of $l$ is as follows:

$$
l=\frac{k z^{*}}{1+k z^{*} / l_{0}},
$$

where $k$ is Karman's constant and parameter $l$ 。 is

$$
l_{\circ}=\alpha_{0} \frac{\int_{0}^{\infty} z^{*} q d z^{*}}{\int_{0}^{\infty} q d z^{*}},
$$

where $\alpha_{0}$ is empirical constant $(=0.1)$ and $q$ is the square root of turbulent energy. There exists another expression of $l_{0}$.

For example, according to Blackadar (1962) :

$$
l_{0}=0.00027 \mathrm{Vs} / \mathrm{f} \text {, }
$$

and according to $\mathrm{Wu}(1965)$ :

$$
l=0.006 u_{*} / f
$$

where Vs, $\mathrm{f}$ and $u_{*}$ are surface wind, Coriolis parameter, and friction velocity respectively. According to our tests, the formulation of Mellor and Yamada seems to be a little better than the others'.

In relation to diffusion processes, a constant flux layer is assumed in the lowest level to estimate sensible and latent heat flux and momentum flux, and we use the universal functions of Kondo et al. (1978).

\section{(2) Condensation processes}

The moist thermodynamic processes including phase change may be treated prognostically because of our model scale and grid interval. The parameterization scheme of moist convective adjustment, however, is employed for the purpose of making clear the influence of the interaction between cloud and radiative process in the local circulation.

The scheme of moist convective adjustment of Kurihara (1973) is employed in Cases 3 and 4 because this method does not need to determine the critical relative humidity and includes the effect of entrainment in criterion of free moist convection.

The important points of his scheme will be given briefly in order. The adjustment process is divided into large--scale. condensation, dry convective adjustment and moist convective adjustment. Each adjustment is treated from the top to the surface layer.

\section{(i) Large-scale condensation}

We check the moisture field of the layer $\mathrm{k}$. If it is in a state of supersaturation, $\mathrm{T}$ and $\mathrm{r}$ are changed to $T+\Delta T$ and $r+\Delta r$, respectively, under the condition that $\mathrm{C}_{p} \Delta T+L \Delta=0$ to make the relative humidity $100 \%$ after the adjustment. This process may be written as and

$$
T_{k} \rightarrow T_{k}+\Delta T_{k}, r_{k} \rightarrow r_{k}+\Delta r_{k}=\left(r_{s}\right)_{k}
$$

$$
\mathrm{C}_{p} \Delta T_{k}+L \Delta r_{k}=0
$$

where $r_{s}$ denotes the saturation mixing ratio.

(ii) Dry convective adjustment

Next, we check the stability. Since the density considered here is that of moist air, the virtual temperature $T_{v}$ is corrected whenever the stratification is absolutely unstable under conditions involving conservation of the total potential energy and moisture content. And the stability is adjusted to the dry adiabatic lapse rate.

Virtual temperature is expressed approximately as

$$
T_{v}=T+0.61 \vec{T} r
$$

where $\bar{T}$ is the mass-weighted average temperature for the two levels and is invariant for the exchange of heat between the levels.

If the corrections for $T$ and $r$ are assumed to be obtained by multiplying the correction for $T$ by the lower-level values of $T / T_{v}$ and $r / T_{v}$ respectively, corrections of $T$ and $r$ can be determined uniquely.

(iii) Moist convective adjustment

When it is conditionally unstable between 
two given levels, the possibility of free moist convection is checked by the criterion for the lapse rate of the cloud element with entrainment.

The moist convection becomes favorable in this criterion if the stratification is conditionally unstable, the relative humidity is high, and entrainment into a cloud element is little.

If this condition is satisfied, condensation occurs at the lower level and heat and water vapor are transported from the lower to the upper level. The temperature and mixing ratio of all sets of two sequential layers are modified from top to bottom layer. These steps are repeated until the whole air column becomes neutral or stable for the free moist convection.

There is one problem to completing this scheme as pointed out by Kurihara: the numerical results are affected remarkably by the determination of the characteristic size of a cloud. We adopted the value of $100 \mathrm{~m}$ by trial and error.

To summarize about the convective adjustment processes, We can say as follows.

When the stratification is conditionally unstable and the relative humidity of the layer exceeds the limited value, cumulus convection occurs.

The stratification is adjusted to the moist adiabatic lapse rate, the relative humidity becomes the critical level and the layer warmed by a release of latent heat.

\section{(3) Radiative process}

The main purpose of this study is to test the effects of clouds on the local circulation through the change of radiative processes. A simple, accurate and economical parameterization scheme of radiative processes is required. What we must calculate is the radiative flux divergence to calculate the radiative heating or cooling rates of the atmosphere including clouds and the ground surface. Since the vertical thickness of our model atmosphere is about $6000 \mathrm{~m}$, parameterization should include the combined effects of absorption and scattering by the trace gases of $\mathrm{H}_{2} \mathrm{O}$ and $\mathrm{CO}_{2}$ together with clouds. The parameterization schemes of radiative processes for numerical models have been reported by Rodgers and Walshaw (1966),
Manabe and Wetherald (1967), Katayama (1972), Liou and Wittman (1979) and others. Now we calculate the radiative fluxes with reference to Katayama's scheme because of its simplicity.

We would like to discuss in brief the difference between the scheme of Kimura and Arakawa (1983) and that of Katayama (1972). The former scheme is adopted in Cases 1 and 3, the latter in Cases 2 and 4.

\section{(i) Longwave radiation}

Longwave radiation considered in Cases 1 and 3 is only for the earth's surface, while the downward flux mainly emitted from water vapor in the atmosphere is calculated by the method of the Yamamoto radiation chart. Downward radiation from $\mathrm{CO}_{2}$ is given by a linear function of temperature in the lowest -level atmosphere (Elsasser method).

On the other hand the scheme used in Cases 2 and 4 is essentially the same as that of Yamamoto. But we take into consideration the net radiation at each atmospheric layer and the ground surface permitting the existence of clouds.

The model layer is considered to be a cloud layer if the water vapor mixing ratio of the layer exceeds its saturation value.

The possible cases of cloud formation in our model are:

1. clouds associated with grid-scale supersaturation.

2. clouds associated with subgrid-scale cumulus convection.

3. stratus clouds associated with supersaturation within the planetary boundary layer.

The top and bottom of the cloud are assumed to emit black body radiation at their respective temperatures. Further assumptions are made regarding the geometrical character of clouds :

1. clouds are defined in layers; there may be as many cloud layers as the number of our model layers,

2. the thickness of a cloud is equal to the thickness of the model layer in which it is located,

3. the fractional cloudiness of a cloud layer is unity. 
(ii) Shortwave radiation

The solar radiation in Cases 1 and 3 is composed of direct solar radiation $\mathrm{SR}$ and diffuse radiation $\mathrm{DR}$. The direct solar radiation on a slant surface is given by

$$
\mathrm{SR}=\mathrm{S}_{0} \mathrm{~A}^{m} \cos \mathrm{i} \text {, }
$$

where $S_{0}$ is the solar radiation which reaches the top of the atmosphere, A the transmission coefficient, and $\mathrm{m}$ the path length into the atmosphere. Incident angle $i$ on slopes is given by latitude, the declination of the sun, the hour angle and slope azimuth. The diffuse radiation is calculated as follows (List, 1971): the total solar radiation is absorbed by $\mathrm{H}_{2} \mathrm{O}$ and $\mathrm{O}_{3}$ for $9 \%$ in the atmosphere. The diffuse radiation is regarded as the remainder between this reduced radiation and direct solar radiatios SR. Half of this diffuse radiation is assumed to reach the earth's surface; i.e.

$$
\mathrm{DR}=\left(0.455-\mathrm{A}^{m} / 2\right) \mathrm{S}_{0} \sin \mathrm{H},
$$

where $\mathrm{H}$ is the elevation angle of the sun.

The total solar radiation is

$$
\mathrm{S}=(1-\alpha)(S R+D R) \sec \delta \text {, }
$$

where $\delta$ is the slope angle and $\alpha$ the albedo which is assumed to be $5 \%$ on the sea surface and $12 \%$ on the ground surface.

On the other hand the scheme used in Cases 2 and 4 becomes complicated due to effect of cloud existence. Katayama (1972) divided the solar radiation into two components concerning the wavelength $\lambda$ : for $\lambda<0.9 \mu$, with an error of a few percent, solar radiation is assumed to be Rayleigh-scattered and not absorbed by water vapor; while for $\lambda>0.9 \mu$, the converse is assumed.
The solar radiation incident at the top of the atmosphere is then separated as

The scattered part : $\mathrm{SP}=0.651 \mathrm{~S}_{0} \cos \theta$

The absorbed part : $\mathrm{AP}=0.349 \mathrm{~S}_{0} \cos \theta$, where $\vartheta$ is an incident angle on the slope.

The four basic factors contributing to the depletion of solar radiation and assumed:

1. absorption by water vapor

2. Rayleigh scattering by air molecules

3. reflection by cloud

4. absorption by cloud

Absorption and Mie scattering by aerosol particles are neglected.

What we must calculate is the absorption by atmospheric layer and by the earth's surface in the case of a cloudy atmosphere.

The albedo and absorptivity of clouds are calculated with reference to Rodgers (1967) as in Table 1.

We computed correctly the effects of multi -layer clouds on the albedos for the scattered part.

For the absorbed part, scattering by water droplets, absorption by water vapor and droplets in clouds must be considered. Therefore behavior of the absorbed part in the case of cloud layers becomes very complicated. The following assumptions are made for simplicity : 1. Solar radiation in clouds and radiation transmitted by clouds are diffuse radiation. The effective optical thickness for diffuse radiation is assumed to be 1.66 times for the length of a vertical column.

2. The cloud layer is regarded as a fictious water vapor layer which absorbs the same

Table 1 The albedos and absorptivity of clouds

\begin{tabular}{|c|c|c|c|}
\hline \multirow{2}{*}{ Cloud Type } & Scattered part & \multicolumn{2}{|c|}{ Absorbed part } \\
\cline { 2 - 4 } & Albedo $(\mathrm{Rj})$ & Albedo $(\mathrm{Rj})$ & Absorptivity $(\mathrm{Aj})$ \\
\hline $\begin{array}{c}\text { Low cloud } \\
\mathrm{Z}^{*}=0 \sim 1,000 \mathrm{~m}\end{array}$ & 0.66 & 0.50 & 0.30 \\
\hline $\begin{array}{c}\text { Middle cloud } \\
\mathrm{Z}^{*}=1,000 \sim 3,600 \mathrm{~m}\end{array}$ & 0.60 & 0.48 & 0.25 \\
\hline $\begin{array}{c}\text { High cloud } \\
\mathrm{Z}^{*}=3,600 \sim 6,000 \mathrm{~m}\end{array}$ & 0.54 & 0.46 & 0.20 \\
\hline
\end{tabular}


amount of insolation as that absorbed by the cloud. In other words the amount absorbed by a cloud layer can be calculated from the difference between the absorbed amount from the top of the atmosphere to the bottom of the cloud and that from the top of the atmosphere to the top of the cloud.

On the other hand, there may be three types of solar radiation that reaches the earth's surface :

1. The scattered part,

2. the absorbed part that reaches directly, and

3 . the same part from multiple reflections by cloud layers.

Surface albedo is assumed to be $7 \%$ on the sea surface and $14 \%$ on the ground surface.

\section{The computational results}

As stated in the introduction the numerical
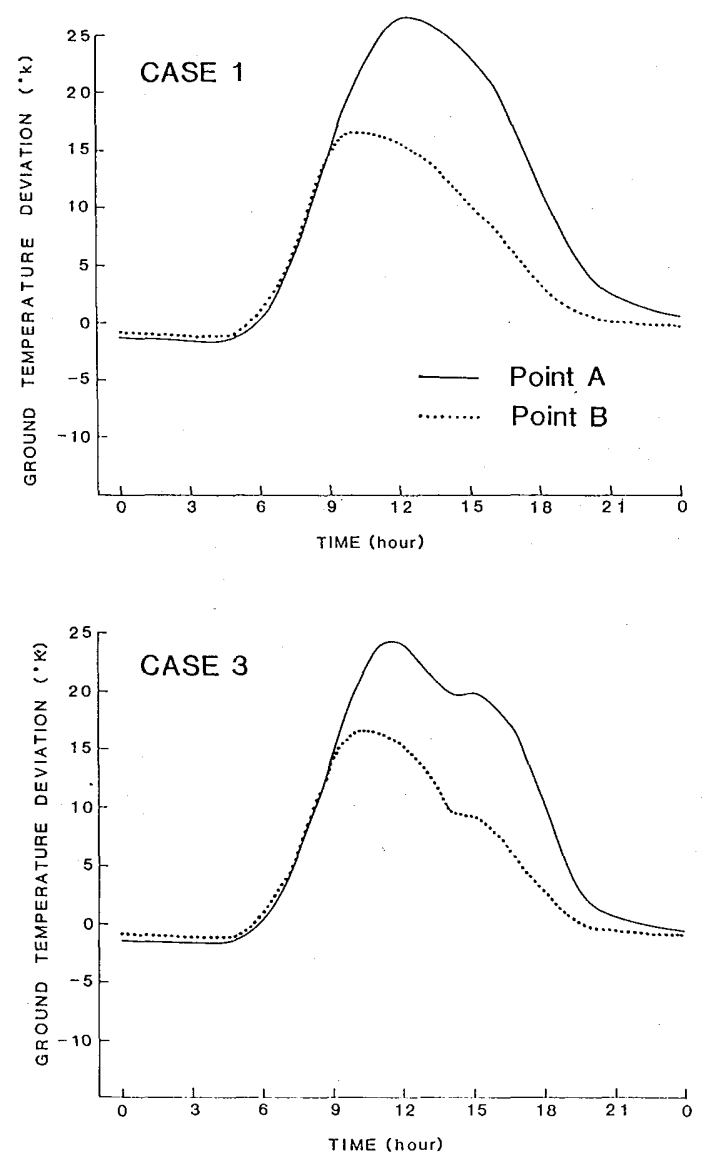

experiments are carried out for four cases to study the basic nature of local circulation influenced by clouds and radiation.

The computation was started at 18 LST of summer solstice and the results of 24 hours after midnight are compared with each other.

The calculations of cumulus convection and radiative process were performed every five steps in the computation.

The results are shown in the following subsections.

(1) Diurnal variations of ground surface temperature

Ground surface temperature has an important effect upon air temperature near the earth's surface. Fig 2 shows the diurnal variations of the calculated ground temperature deviations from the initial values at point
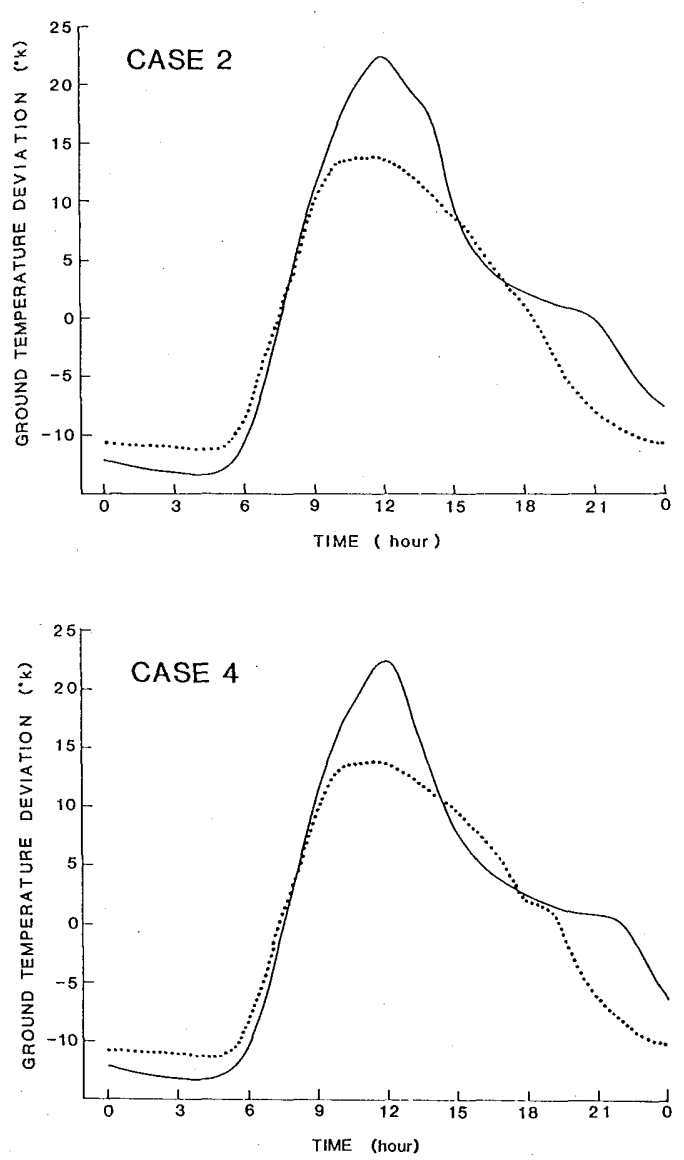

Fig. 2 Diurnal variations of the ground surface temperature of each case 
A (at the mountain top) and point B (200 m height on the east slope and $25 \mathrm{~km}$ far from the coast). The reason we selected these points is that we can examine the radiative effects of clouds for surface temperature; i.e. the mixing ratio of layers over point $A$ exceeded its saturation value in the afternoon of the time integration.

In the figure, the solid line shows the time variation of surface temperature at point $A$ and dashed line that at point $\mathrm{B}$, respectively.

First of all, what we can say from the figures is that there are considerable differences between the results of Cases 1, 3 and Cases 2,4 on the depressions of temperature in the nighttime. The cooling rates of Case 1 and Case 3 are distinctly weak and the values of minimum temperatures occurring just after sunrise (04: 40 LST) differ not so much from the initial value.

The results of computation for the next day are almost the same as those for this day. The main reason for the difference in the depression in the nighttime may be the different treatment of the radiative process.

The net radiative fluxes at the ground are calculated in all cases. But we do not take into consideration the heating or cooling rate due to
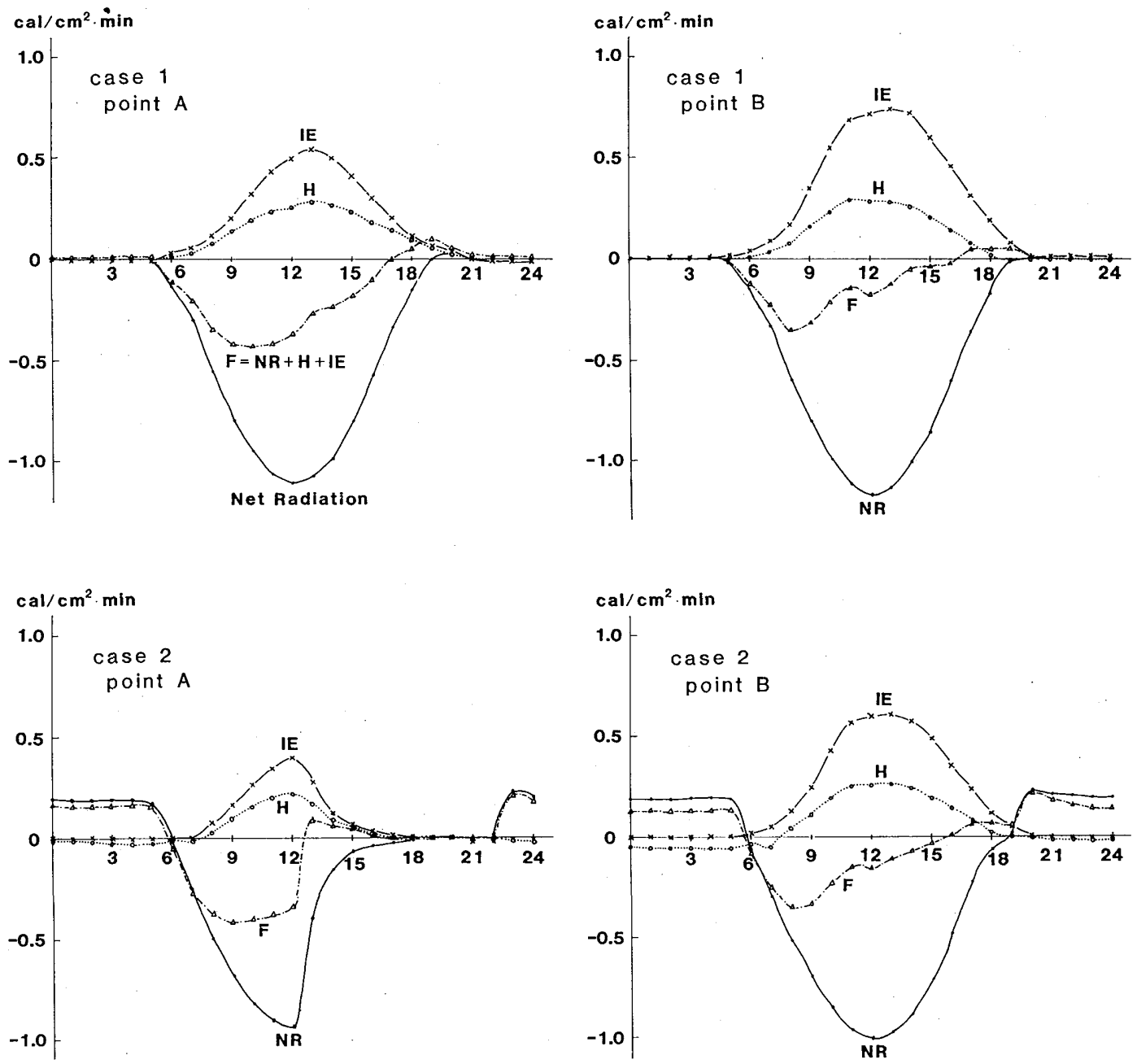

Fig. 3 Diurnal variations of the heat 
long-and shortwave radiations in the atmosphere in Cases 1 and 3 .

The net upward radiative flux can be experssed as the difference between the outgoing radiative flux from the surface and the incoming atmospheric one which is the function of temperature and effective water vapor amount and increase function of them.

The temperature near the ground surface, as might be suspected, must drop mainly due to the difference between the net radiative flux of the ground surface and that of the lower atmosphere. The calculation of the cooling or heating rate by the radiative processes is neglected in Cases 1 and 3 , and the value of the net upward flux becomes small due to the overestimation of the incoming radiative flux.

Consequently the ground surface temperature in Cases 1 and 3 becomes quite insufficient.

Eig. 3 shows the diurnal variations of the heat balance at the ground surface of points $\mathrm{A}$ and $B$. The sensible heat flux $H$, latent heat flux $\mathrm{lE}$, net radiative flux $\mathrm{NR}$ and the sum of them $F$ are plotted with positive values for upward fluxes. The value of $\mathrm{F}$ corresponds to the heating rate of the ground surface temperature as seen from equation (7).

The NR and F of Case 1 and 3 in the
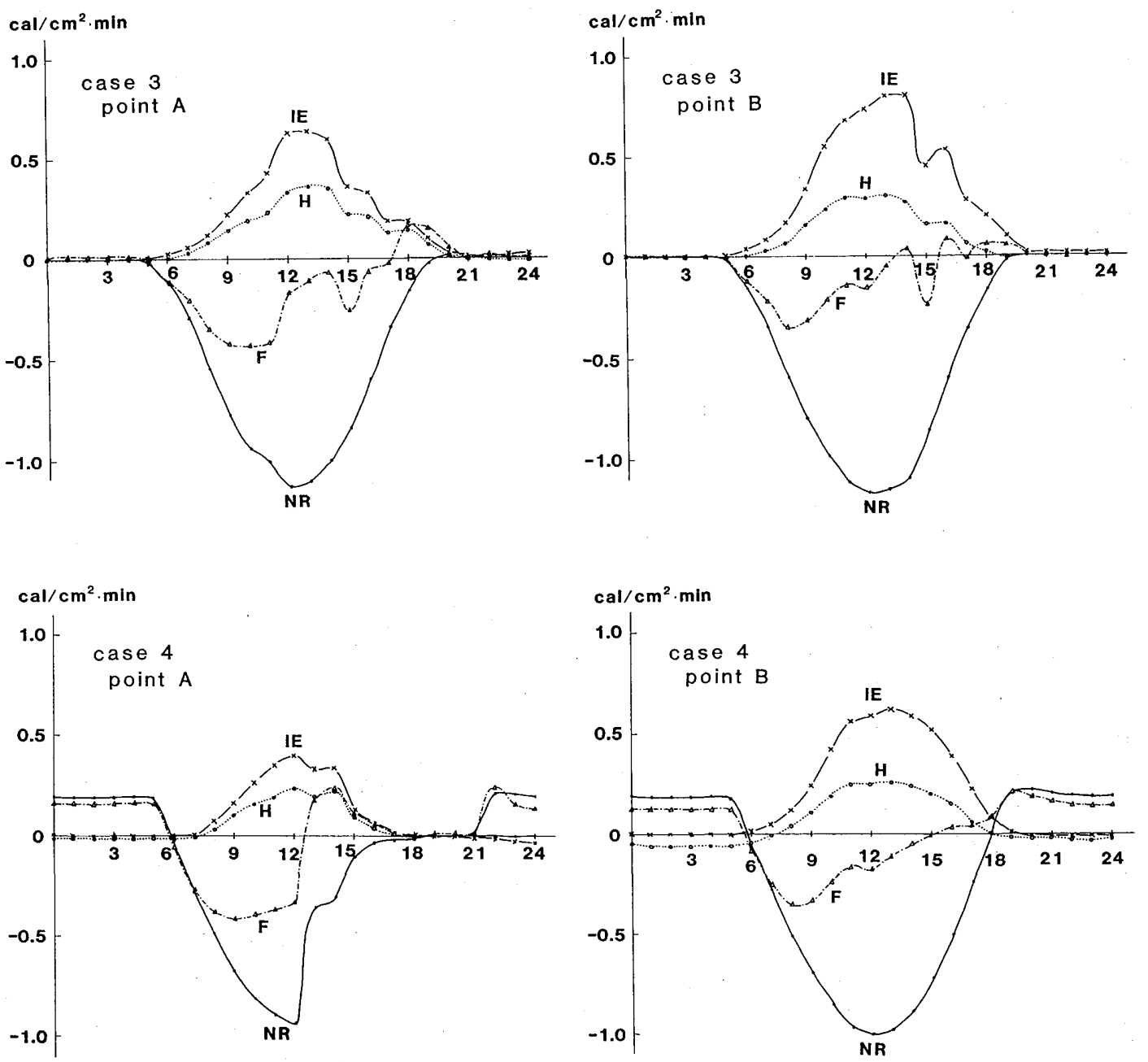

balance of each case at points $\mathrm{A}$ and $\mathrm{B}$. 
nighttime show very small value compared with Cases 2 and 4 . It may be necessary to include the radiative heating or cooling process in the atmosphere for simulating the depression of the ground temperature in the nighttime.

Furthermore, we have to point out the difference among the depressions of temperature in the afternoon. The ground surface temperature continues to rise rapidly with time after sunrine. But the temperature at point $\mathrm{A}$ in Cases 2 and 4 falls rapidly from about $12: 00$ LST and the depressions of the temperature go down from evening, then the temperature decreases rapidly once more from about $21: 00$ LST. On the other hand at point $B$ the temperature falls down steadily all afternoon. The influence of "clouds", as might be suspected, seems to be an important factor in this difference.

As stated in the previous section, the layer is considered to be a cloud layer in Cases 2 and 4 if the water vapor mixing ratio of the layer exceeds its saturation value. The effect of "clouds" on the radiative process is taken into consideration in Cases 2 and 4. But in Case 3, layers are not regarded as cloud layers for radiative processs even if there exist convective clouds in the model atmosphere.

Fig 4 shows the time variation of the domains of saturated air in Case 4. Hereafter this saturated layer will be called a cloud layer. In the figure, the numbers vertically arranged show the height measured by $z^{*}$-coordinate. The numbers horizontally arranged are the grid point numbers: The points 12 and 13 , for example, show the central part of the moun-
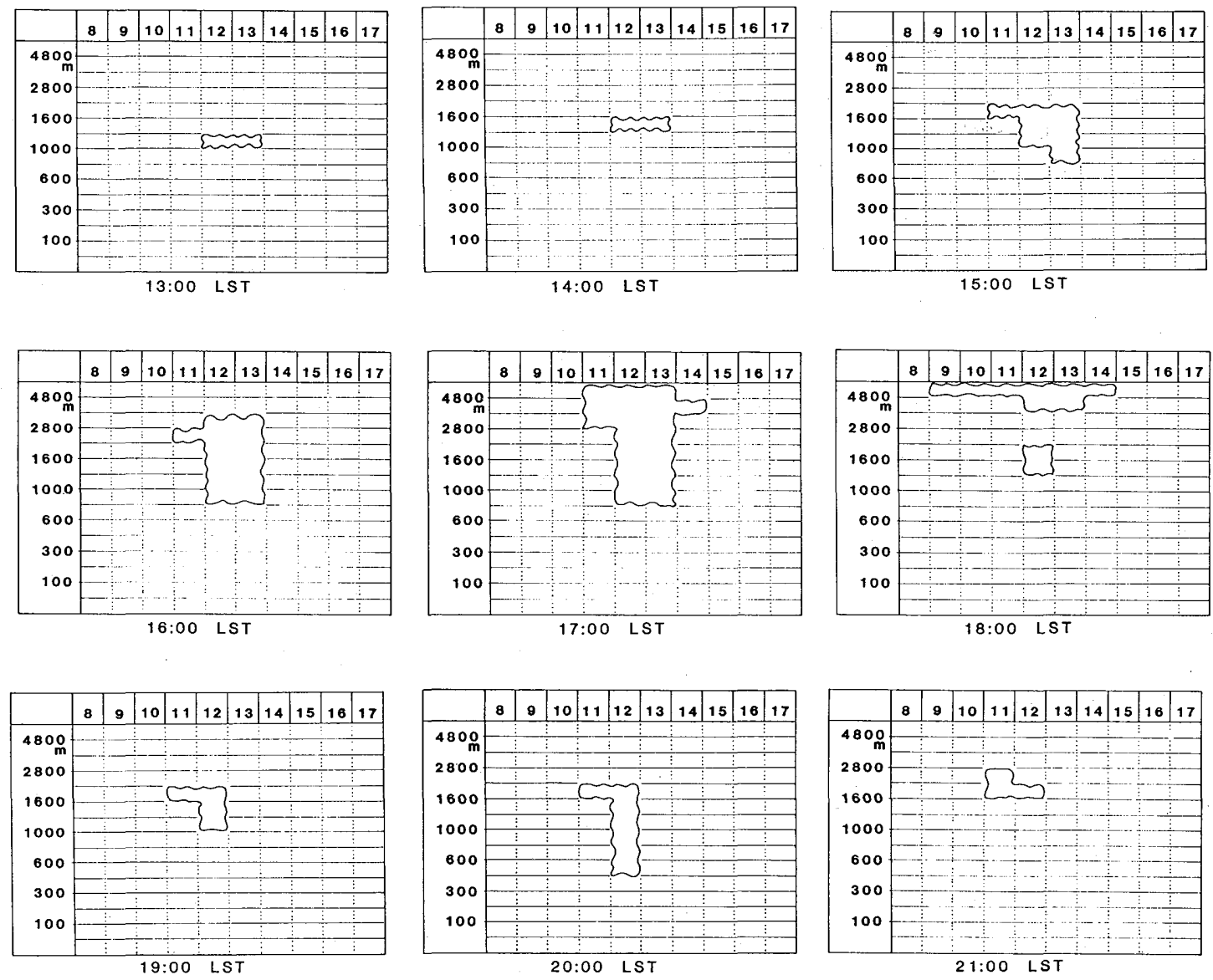

Fig. 4 Hourly change of clouds in Case 4 
tainous area. In this case cloud layers appeared over the mountain top at 12:45 LST and disappeared at $21: 30 \mathrm{LST}$.

We can see that clouds grow up as time goes on in the afternoon, then separate into two layers at about 18:00 LST and become gradually small.

It can be considered, from our results on the ground temperature, clouds and heat balance at the ground, that the rapid fall of the ground surface temperature from about 12:00 LST is caused by these cloud layers.

Namely, a cloud layer appeared at $12: 45$ LST, disapeared after 20 minutes and then appeared once more from $13: 50 \mathrm{LST}$.

Table 2 is some of results on the calculated net long-and shortwave radiation on the ground surface in Case 4. There was no cloud over point $\mathrm{B}$ for the whole day in the numerical simulation, so the vertical distribution of clouds over point $A$ and the value of radiation at both points are tabulated. S.P., D.A.P and M. R. A. $P$ are the values of incoming shortwave radiation to the earth's surface, so the sum of them exceeds the net shortwave radiation.
The values of long-and shortwave radiation are almost the same at both points at 13 : 45 LST, but significant difference between point $A$ and $B$ is recognized after 5 minutes. Net long -and shortwave radiation are changing slowly at point $B$ but the values at point $A$ show a large depression with time.

Especially the net shortwave radiation at the stage of two cloud layers decreases to about $20 \%$ of what it is at that of no cloud layer.

The flux of incoming multi-reflected absorbed part M.R.A.P can be seen due to the appearance of two cloud layers at 14:25 LST.

One should note that the reduction of net radiation itself influenced by clouds is, as is evident from Fig. 3, the main cause of the rapid fall of ground temperature at point $A$ in Cases 2 and 4.

Let us discuss some actual behavior of ground surface temperatures under the influence of clouds. We made meteorological observations of slope wind circulation at $\mathrm{Mt}$. Fuji last year. Fig. 5 shows the observed ground surface temperature on the southeast slope $(2160 \mathrm{~m})$. The data, obtained continuously

Table 2 Influence of clouds on the surface net radiation in Case 4

\begin{tabular}{|c|c|c|c|}
\hline TIME & Radiation at the Ground Surface & $\mathrm{I}=12$ & $\mathrm{I}=19$ \\
\hline $13: 45$ & $\begin{array}{l}\text { Net Longwave Radiation (ly/min) } \\
\text { Net Shortwave Radiation (ly/min) } \\
\text { incoming Scattered Part } \\
\text { incoming Direct Absorbed Part } \\
\text { incoming Multi Reflected } \\
\text { Absorbed Part }\end{array}$ & $\begin{array}{l}0.33 \\
1.24 \\
1.03 \\
0.39 \\
0.00\end{array}$ & $\begin{array}{l}0.32 \\
1.23 \\
1.02 \\
0.38 \\
0.00\end{array}$ \\
\hline 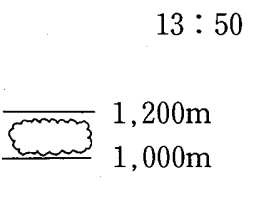 & $\begin{array}{l}\text { N. L. R } \\
\text { N. S. R } \\
\text { S. P } \\
\text { D. A. P } \\
\text { M. R. A. P }\end{array}$ & $\begin{array}{l}0.11 \\
0.49 \\
0.44 \\
0.12 \\
0.00\end{array}$ & $\begin{array}{l}0.32 \\
1.22 \\
1.01 \\
0.37 \\
0.00\end{array}$ \\
\hline 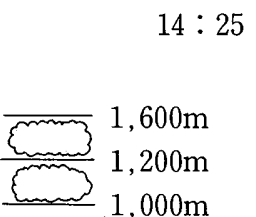 & $\begin{array}{l}\text { N. L. R } \\
\text { N. S. R } \\
\text { S.P } \\
\text { D. A. P } \\
\text { M. R. A. P }\end{array}$ & $\begin{array}{l}0.08 \\
0.27 \\
0.26 \\
0.04 \\
0.02\end{array}$ & $\begin{array}{l}0.31 \\
1.12 \\
0.93 \\
0.34 \\
0.00\end{array}$ \\
\hline
\end{tabular}


by Infra-Red thermometer (IRT), were plotted every five minutes. The regions above the observational point were often covered by cumulus or stratus clouds, which prevented the temperature from falling so much in the nighttime.

The effects of clouds on temperature was so conspicuous in the daytime that a rise or fall of $20^{\circ} \mathrm{C}$ in ten minutes was caused by their disappearance or appearance. The computational results of Case 2 and 4 seems to correspond in general to the observational data.

Next, the difference between Cases 2 and 4 must be considered. Fig. 6 is the diurnal variation of the effective optical thickness $u_{\infty}^{*}$ at both points. Case 4 has a mechanism of upward transportiong of heat and water vapor due to cumulus convection. The effective optical thickness (effective water vapor amount) from the ground surface to the top of

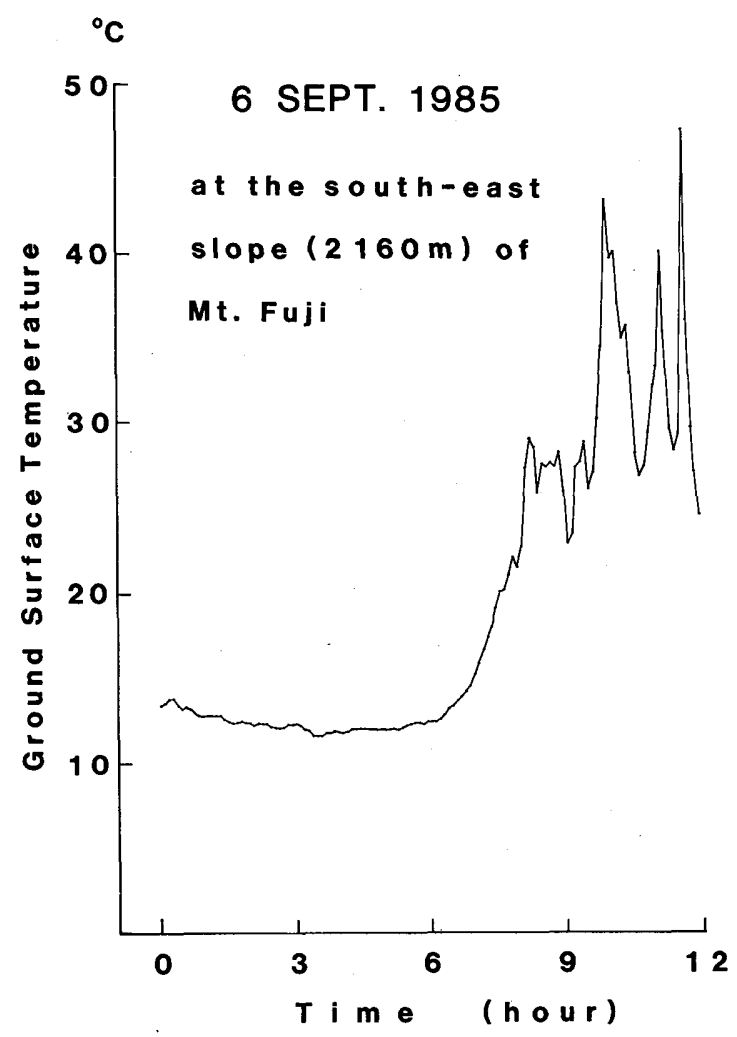

Fig. 5 Observational result of the ground surface temperature at the slope of Mt. Fuji the atmosphere at $I=12$ in Case 4 increases rapidly in the afternoon as compared with Case 2. The results of Fig 2, as might be expected, show that it matters a great deal whether cloud layers exist or not. The effects of the time variation of effective optical thickness on the ground temperature are not so essential in the daytime.

We must refer to the temporarily constant temperatures of Case 3 in the afternoon as compared with Case 1 . We can see that the values of $\mathrm{H}$ and $1 \mathrm{E}$ decrease rapidly from 14 : 00to 15:00 LST. The main reason for this is the transient decreasing of wind speed at points $A$ and $B$ in Case 3, but further details will be given later.

(2) Vertical distribution of potential temperatures

The vertical cross sections of the potential
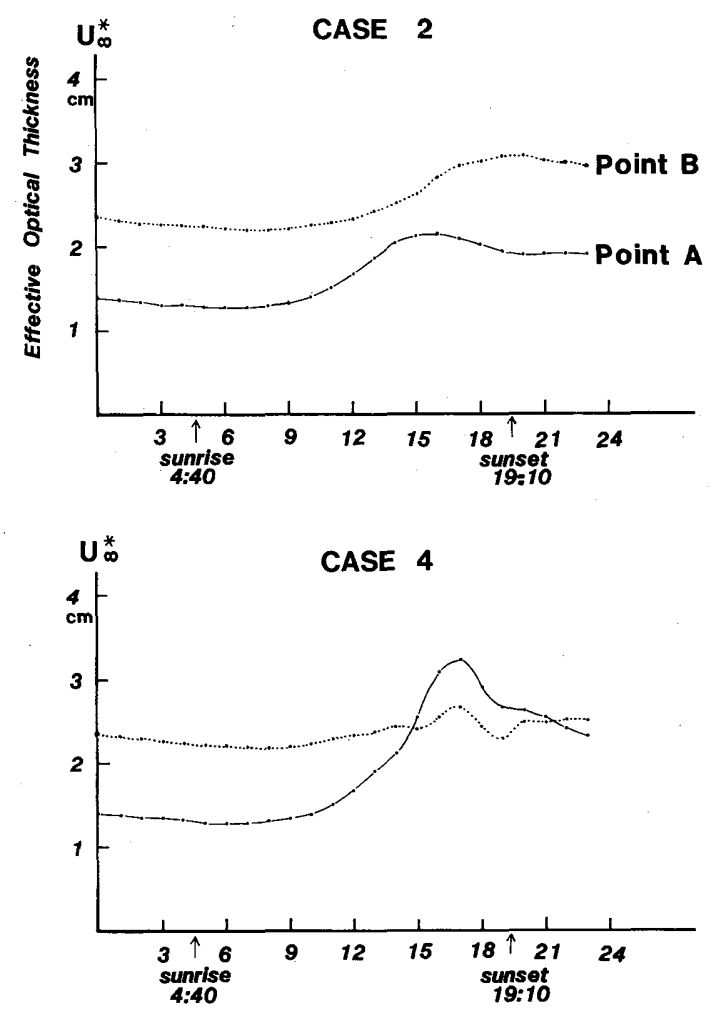

Fig. 6 Diurnal variation of the effective optical thickness in Case 2 and Case 4 
temperature deviation in each case are shown in Fig 7 at intervals of 6 hours from 3 LST. Some of their characteristics will be described in the following.

The results of Case 1 at $3: 00$ LST is almost the same as at the initial stage, i.e. 18: 00 LST. As mentioned in the previous subsection, the cooling rate of the ground surface temperature of Case 1 is quite insufficient. Owing to the lack of radiative cooling effect in the atmosphere, the lower atmosphere is not cooled and no surface inversion layer is formed at all. Then we can see a mixing layer already formed up to about $500 \mathrm{~m}$ over the mountain slope at 9:00 LST.

The most developed stage is reached at about $15: 00 \mathrm{LST}$. In this stage we can see that the temperature of the layer (about 2000-3000 $m$ height) over the mountain top is lower than that of the environs. The entrainment at the top of the mixing layer driven mainly by buoyancy seems to be strengthened by the mountain. This suggests that the mesoscale penetrative convection can be simulated by Case 1. The lower part of the atmosphere is not cooled yet at $21: 00 \mathrm{LST}$.
P.TEMP.DEV. DEG J=2 LT $=3$,

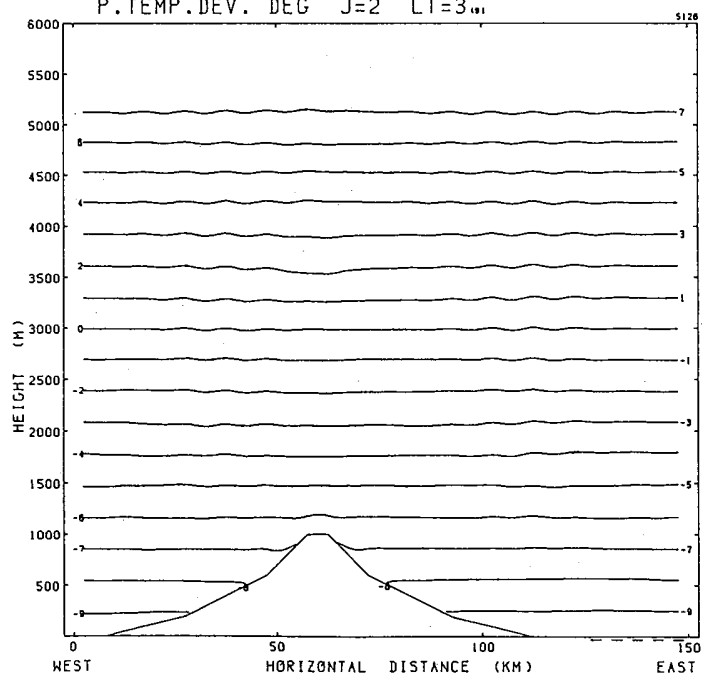

P.TEMP.DEV. DEG J $=2 \quad L T=15$ *21

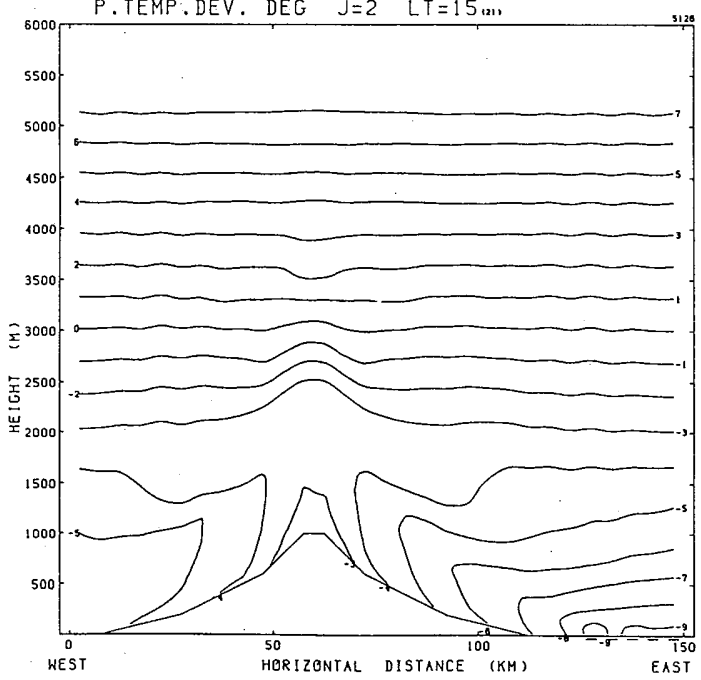

P. TEMP.DEV. DEG J $=2 \quad L T=9$ (Is)

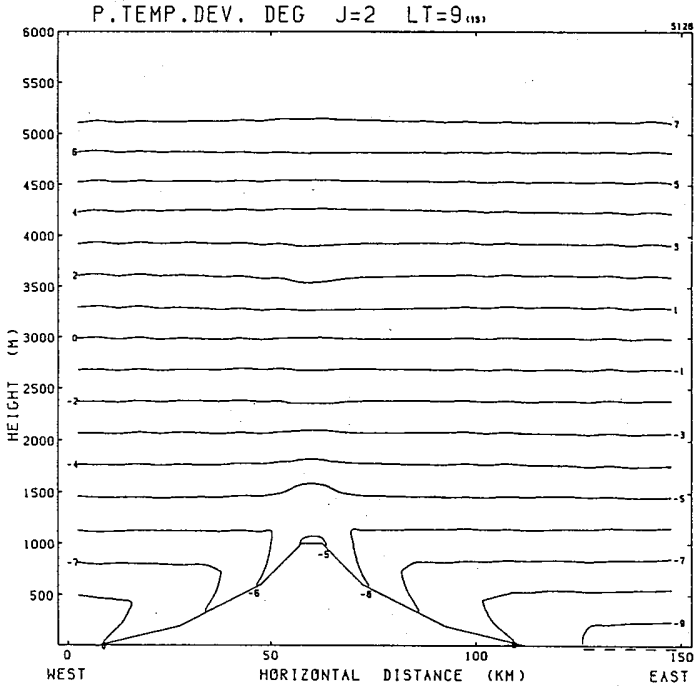

P.TEMP. DEV. DEG J $J=2 \quad$ LT $T=21 \mathrm{~cm}$

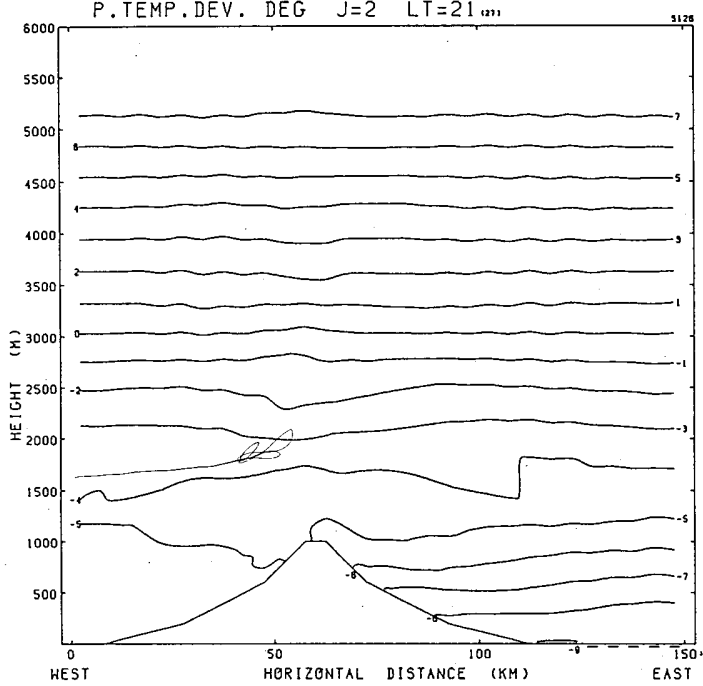

Fig. 7a Potential temperature fields of Case 1 
The results of Case 2 are considerably different from Case 1. The inversion layer can be seen up to about $200 \mathrm{~m}$ from the surface at 3:00 LST by transforming the potential temperature deviation to the temperature field. This result appears to be the strongest proof that the net flux in the atmospheric layer as well as at the ground surface must be taken into consideration for the simulation of the nocturnal inversion layer.

The mixing layer grows slower than that of Case 1 at 9:00 LST and there still remains this trend at the most developed stage, i.e. 15 :
00 LST. This difference could be explained as follows: The surface temperature at the slope in Case 1 is higher in early morning, so the mixing layer can be formed easily by solar radiation.

The effects of clouds must be considered in addition. The ground surface temperature and the atmosphere are not affected very much in Case 1 when the water vapor mixing ratio exceeds its saturation value. On the other hand the ground-surface temperature in Case 2 changes quickly in response to clouds as is evident from Fig. 2 and 3. Relative humidity
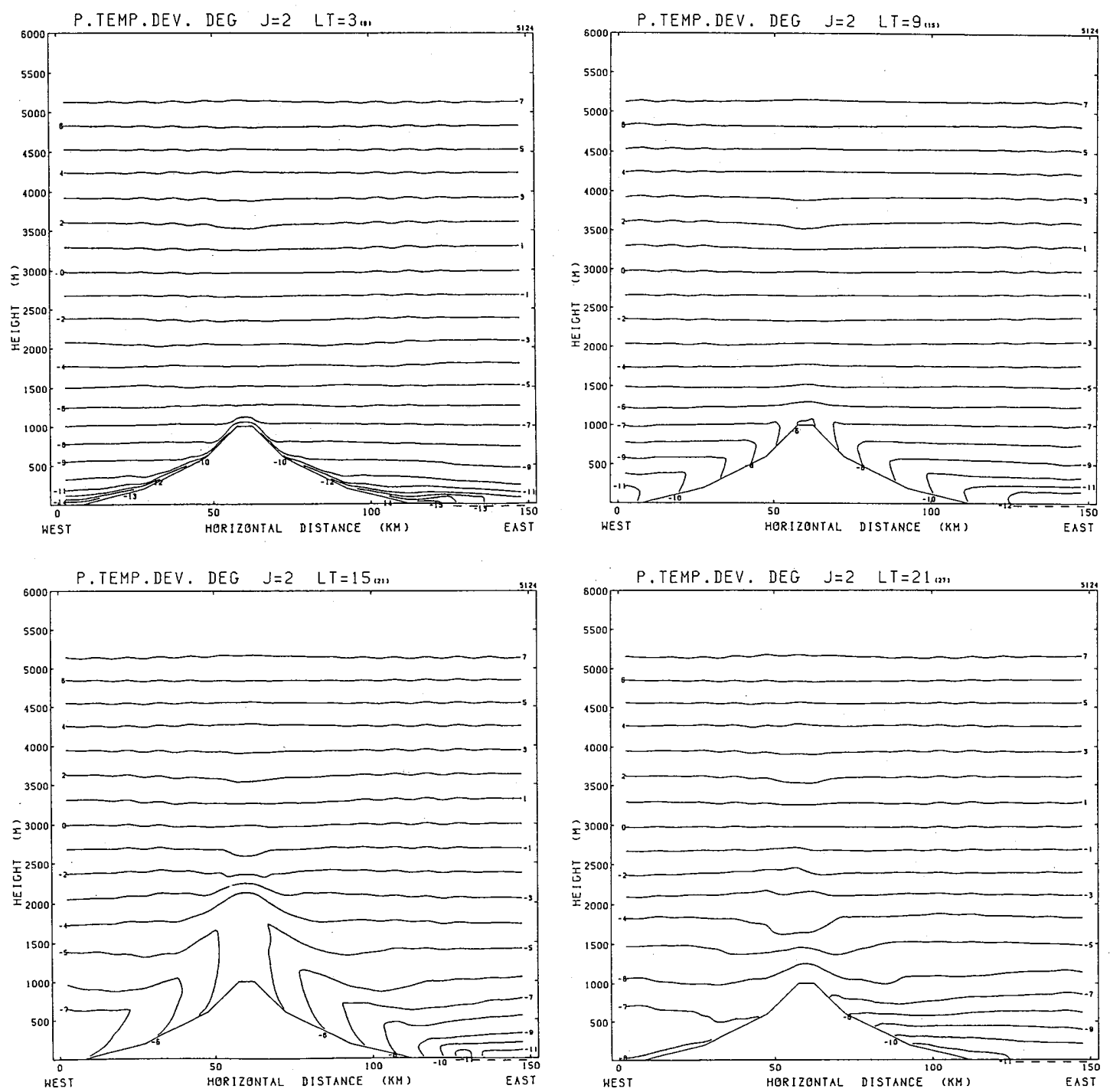

Fig. 7b Same fields of Case 2 
over the mountain in Case 2 exceeds $100 \%$ after 12:00 LST corresponding to the rapid fall of the ground surface temperature. The mixing layer over the mountain top may not develop so much, because vertical transports of momen. tum and heat are suppressed through the small amount of fluxes from the ground surface. The inversion layer begins to develop as $21: 00 \mathrm{LST}$ in Case 2 but not in Case 1.

The results of Case 3 agree with those of Case 1 in the morning as a matter of course. But there is a big difference between Case 3 and the others at the most developed stage. The transport of momentum and heat due to cumulus covection reaches to the top layer of the model atmosphere, and this shows there still remain some problems in our numerical meso -model concerning the usage of the convective adjustment scheme alone.

Unreasonable result, indeed, is obtained about the wind and temperature field by furter numerical integration in Case 3.

The results of Case 4, however, are in agreement with Case 2 in the morning, but there is a big difference between Case 4 and the others at 15:00 LST. To mention a few of the
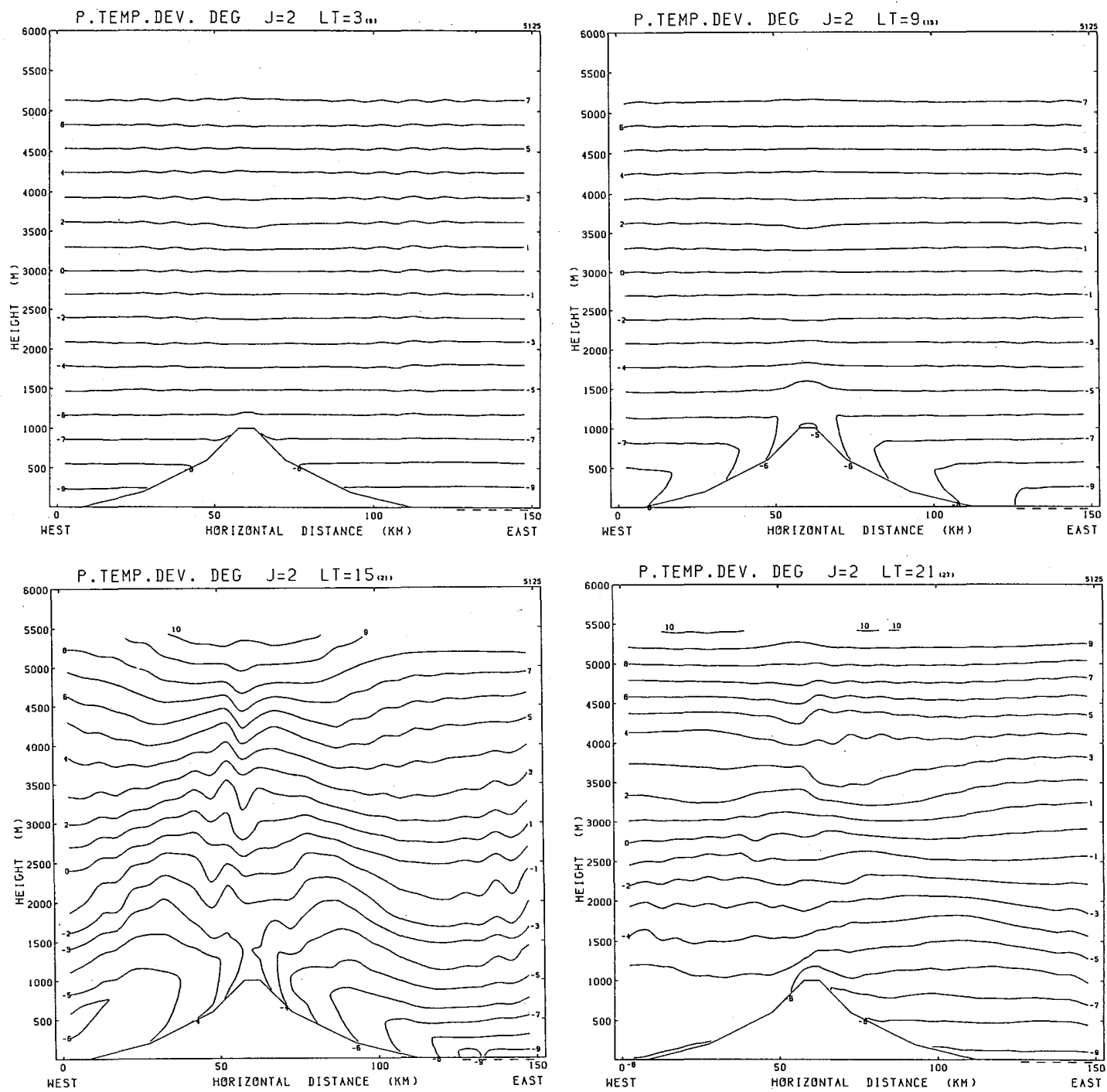

Fig. 7c Same fields of Case 3 
features of Case 4, the mixing layer is not so thick above the top of the mountain, the layer from 2000 to $3000 \mathrm{~m}$ height is warmer than the environmental air, the upper layer (about 3000 $-4000 \mathrm{~m}$ ) is cooler than the environs. The following will give an explanation about this difference :

The mechanism of slope or valley wind circulation is, as is generally known, such that at a given height within the influence of slope heating in the daytime, pressure will become lower than at a point further away from the slope. Consequently, a horizontal pressure gradient from plain to slope is created and upslope wind results.

Circumstances are different if the sky on the mountain top is clouded over. The pressure gradient force is weakened through the rapid fall of the ground surface temperature as stated in the previous sub-section. Consequently an upslope wind system and a mixing layer do not develop so much in the afternoon.

Next, a few comments will be made on those points pertinent to the warming and cooling over the mountain top. The height of the mixing layer over a mountain indicates 700
P. TEMP.DEV. DEG J $\mathrm{J}=2 \quad \mathrm{LT}=3$ m

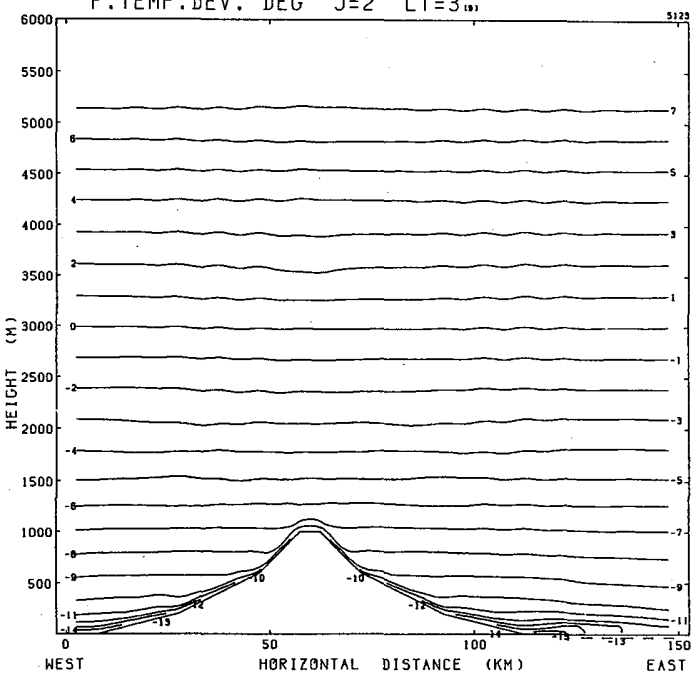

P. TEMP. DEV. DEG J $=2 \quad L T=15 \ldots$

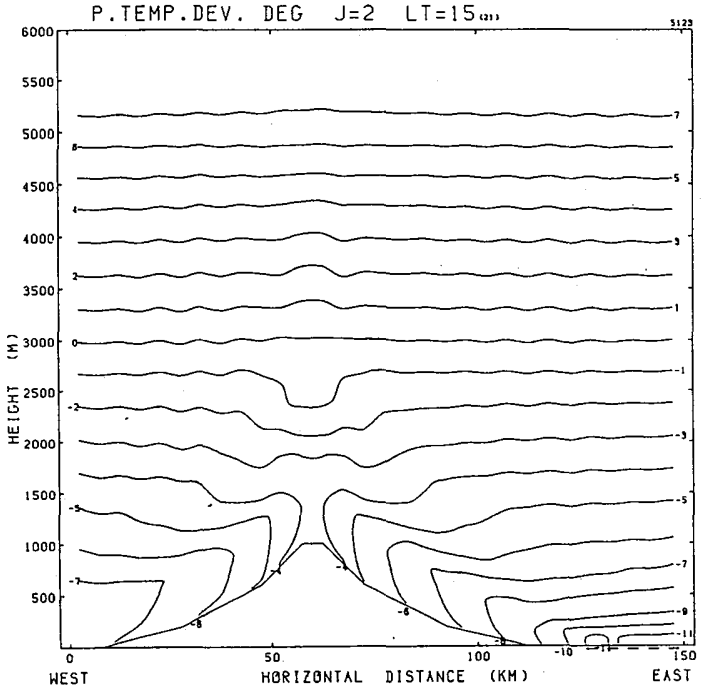

P. TEMP.DEV. DEG $J=2 \quad L T=9$ a,

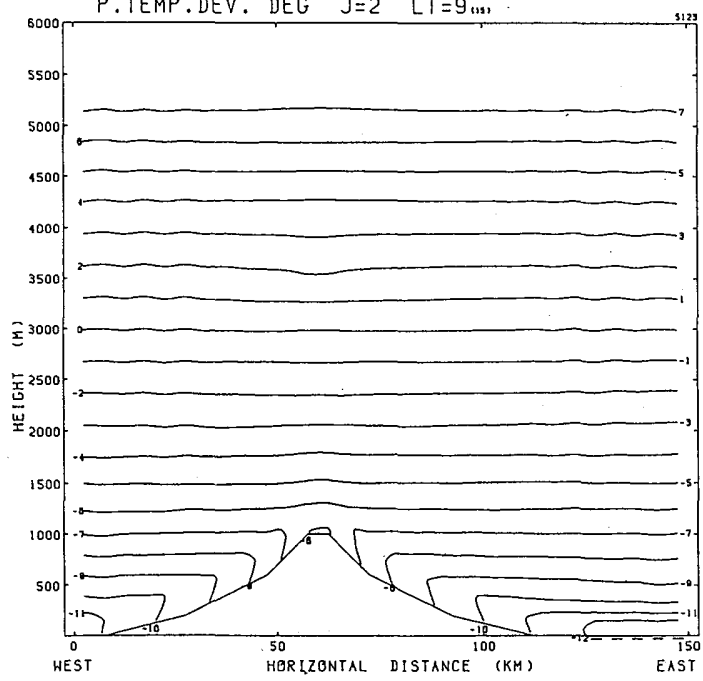

P.TEMP.DEV. DEG J $\mathrm{J}=2 \quad L T=21 \mathrm{am}$

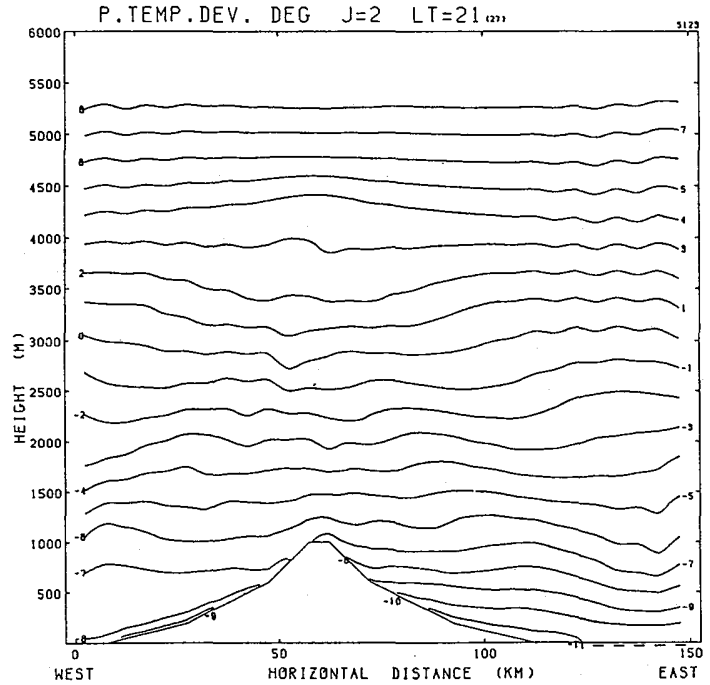

Fig. 7d Same fields of Case 4 
$-800 \mathrm{~m}$ from the numerical results of potential temperature deviation. The cloud layer at 15 : 00 LST can be seen from the top of the mixing layer up to about $3000 \mathrm{~m}$ as in Fig. 4, and the diabatic heating due to condensation can be seen just at the cloud layer.

The influence of interaction between longwave radiation and clouds may be considered concerning the weak cooling at the upper layer and the upper part of the cloud layer (3000 $-4000 \mathrm{~m}$ height from Fig. 7). The upward and the downward longwave radiation balance in the cloud layer, but the former increases over the latter in the upper part of the cloud layer and the layer just above. Radiative cooling may occur as a consequence.

We may conclude from Cases 3 and 4 that the calculation of the shortwave and longwave radiative heating stabilizes the numerical simulation if we introduce the convective adjustment scheme.

At 21:00 LST a thin and weak inversion layer is formed at the lower part of the slope, but around the summit of the monutain the cloud cover still obstructs its appearance.
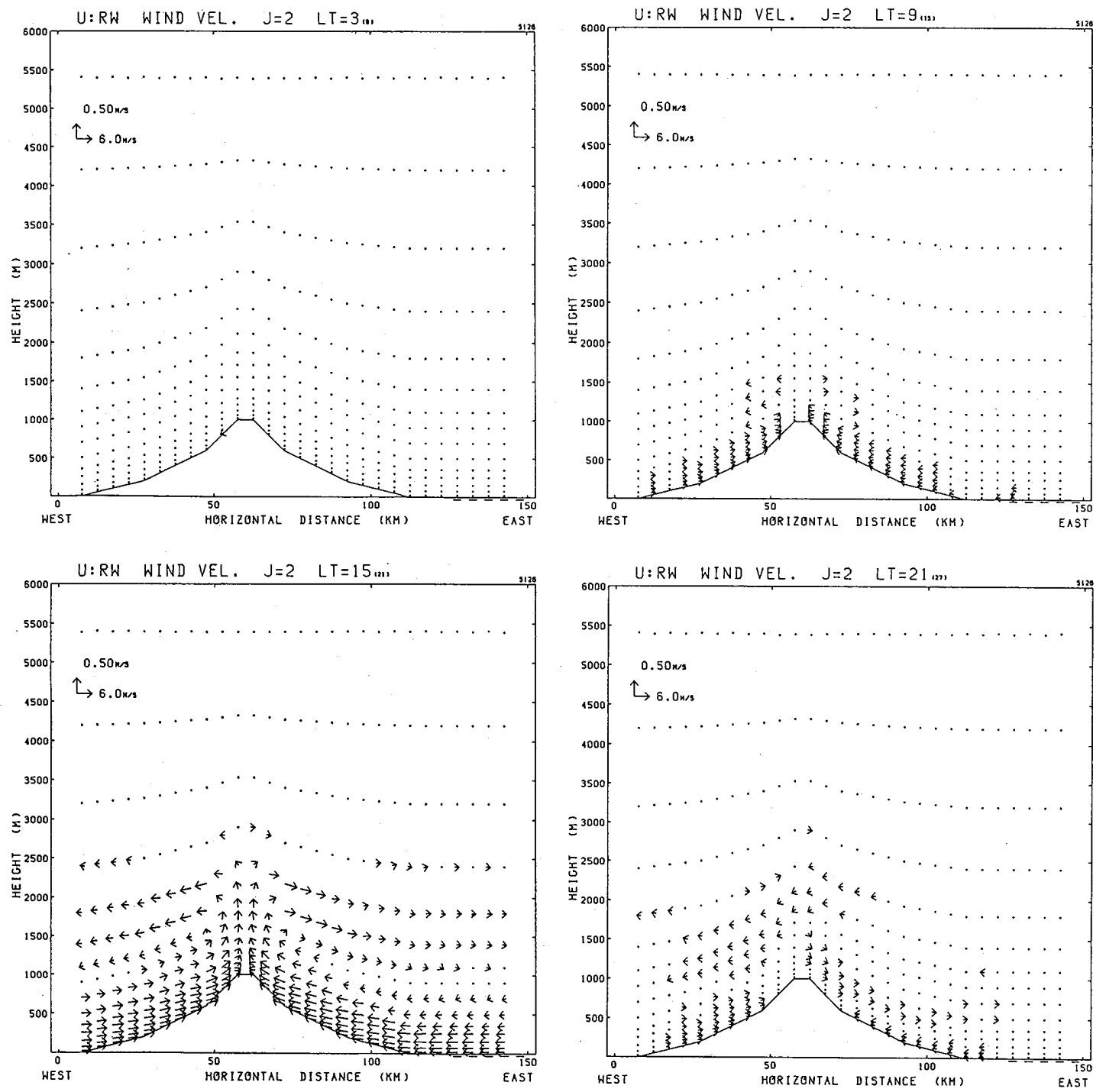

Fig. 8a Component wind fields of Case 1 
(3) Vertical cross section of the wind fields

Fig. 8 shows the vertical cross sections of the wind fields at the same time as Fig. 7.

The downslope (mountain) wind is not simulated in Case 1 or 3 at $3: 00$ LST due to the insufficiency of pressure gradient force as the surface temperature of the mountain slope does not fall in the nighttime. The slope (valley) and anti-slope wind system can be recognized already at 9:00 LST in both Cases. As is analogized from the previous sub-section, the results of Cases 2 and 4 differ from Cases 1 and 3. We can see the thin downslope wind
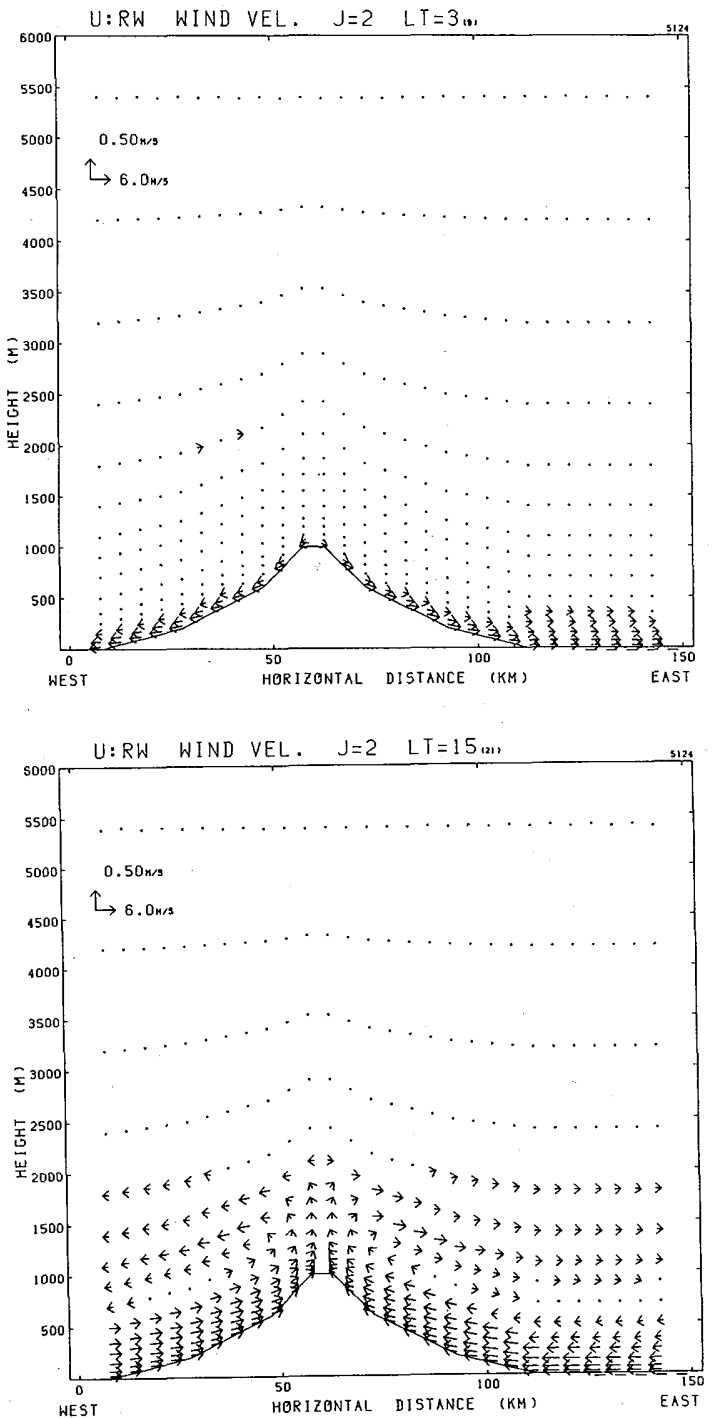

(drainage flow) simulated clearly in Cases 2 and 4 at $3: 00$ LST. This agrees well with the numerical results of Yamada (1982). The weak anti-downslope wind can be seen at the same time of the next day. From the facts described above and in the previous sub-section, we may draw an interesting conclusion that the thin drainage flow shows one-to-one correspondence with the thin nocturnal inversion layer, i.e. the radiative process must be included both on the ground surface and in the atmosphere in a numerical model to simulate accurately the slope and valley wind circulation.
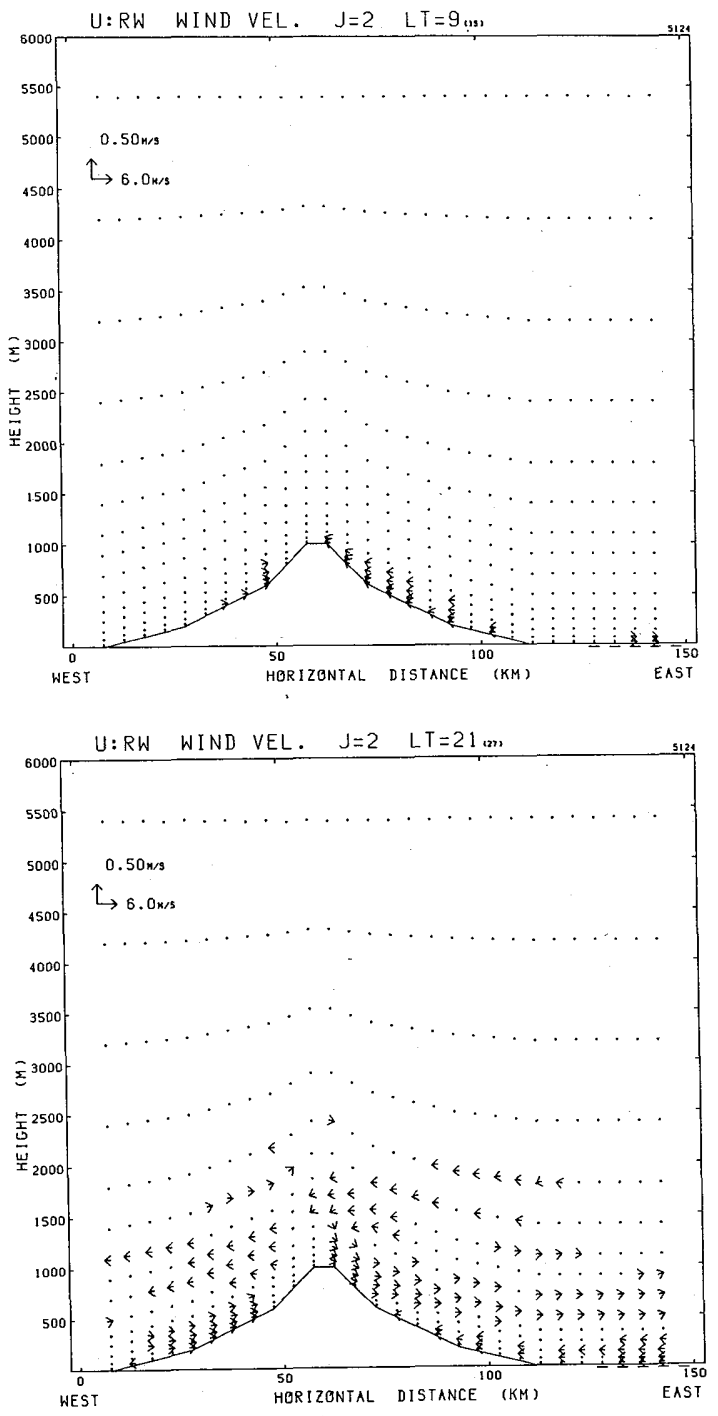

Fig. $8 \mathrm{~b}$ Same fields of Case 2 
Furthermore, one can point out from the figure that this drainage flow becomes thick in a plain area.

The slope wind system is not so strong yet as compared with Cases 1 and 3 at 9:00 LST.

Characteristic features in each case appear at the most developed stage. In Case 1, the typical slope and valley wind circulation can be seen. The depth of an upslope wind system is about $700 \mathrm{~m}$, and from $1000 \mathrm{~m}$ height on the slope anti-slope wind is simulated clearly. Vertical velocity over the mountain can be seen at about $2500 \mathrm{~m}$ height. The circulation, on the contrary, is weak and thin in Case 2.

Especially the vertical velocity is not clear as in Case 1. From the fact that the air over the mountain top is saturated from about 12:00 to 22: 15 LST, we may conclude that clouds have a tendency to suppress the local circulation from the view point of radiative process.

The results of Case 3 are extremely different from the forgoing two cases. The vertical velocity with cumulus convection develops up to the top layer of the model, and we can see two vertical circulations or cells on both sides of the mountain where the upslope
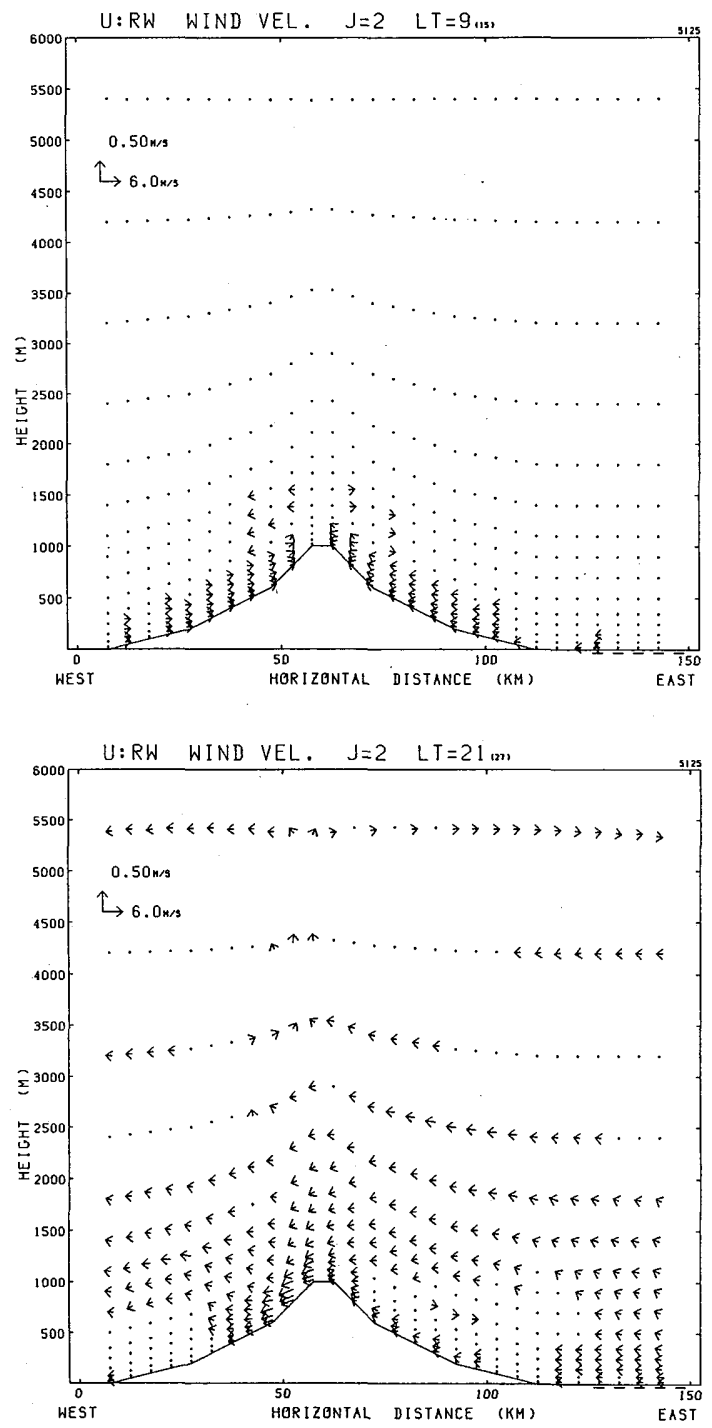

Fig. 8c Same fields of Case 3 
wind near the surface is weakened. This downdraft made the slope wind weak and consequently the surface temperature of point $B$ did not drop temporarily in the afternoon. The anti-slope wind can be seen at the top layer.

We may conclude that the scheme of convective adjustment involves some problems to be solved when it is introduced to the numerical simulation of local circulaton as mentioned above.

Case 4, however, is somewhat similar to Cases 1 and 2. The results may be summarized as follows: the upslope wind system is almost the same as the other cases. But the vertical velocity over the mountain top reaches about $3500 \mathrm{~m}$ height (corresponding to the cloud layer in Fig. 4), stronger than the other cases. The anti-slope wind is not so clear as in Case 1.

Furthermore, we can draw the interesting conclusion from further numerical integration that the introduction of the radiative process not only on the ground surface but in the atmosphere may stabilize the integration and make realistic the numerical results, though the scheme of cumulus convection is included in the
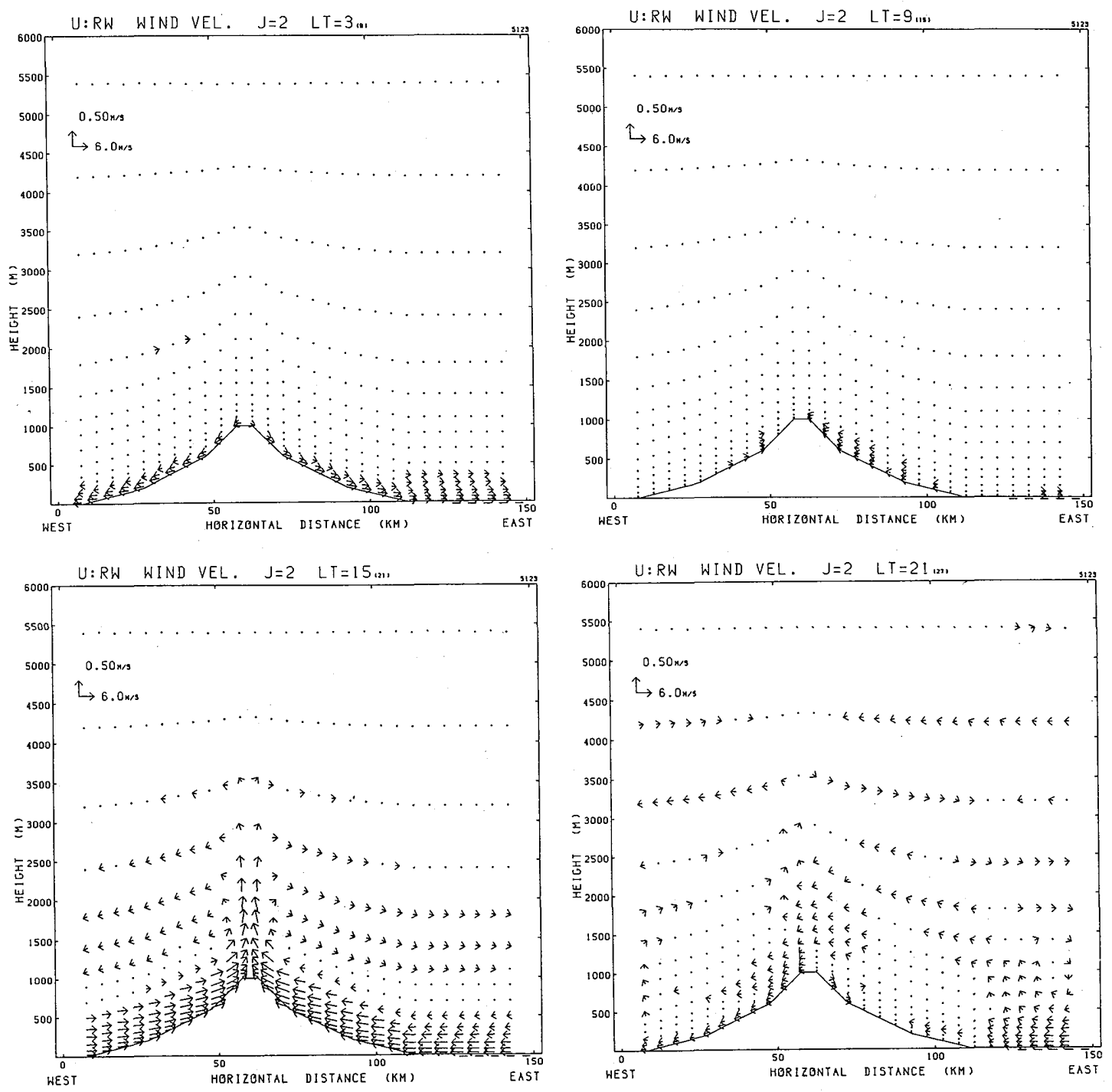

Fig. 8d Same fields of Case 4 
numerical model.

There remains the slope wind circulation at 21: 00 LST in Case 1 due to the insufficient fall of the surface temperature, and the mountain wind does not appear yet in Case 2 .

The mountain wind seems to appear at the west slope in Case 3. But this is not due to the process of radiative cooling. The sea breeze and the slope wind of the east slope, overcoming the slope wind of the west slope, slips out to the west slope in the evening. This west slope wind, strong at midnight, lasts until about 10 : 00 LST of the next day. A precise answer to the cause of this could not be obtained, but it may be considered that the effect of cumulus convection influences the outcome significantly even in the nighttime.

A weak mountain wind, on the contrary, exists in Case 4. No counter-flow can be seen yet at this stage. The flow at the east slope is weaker than that of the west one due to the influence of the remaining sea breeze current. From the results of Case 4 we can see asymmetric currents: the deep upslope winds and the shallow, weak mountain wind.

This is in agreement with the theoretical and observational results in Atkinson (1981).

From the facts described above, we may conclude that both radiative and convective processes must be taken into account if one wants to simulate the local circulation including clouds and to compare the results with the observational data and the theory.

\section{Conclusion}

The influences of clouds on the local circulation were examined by the numerical model using simple schemes of condensation and radiation processes.

It has become clear that clouds exert great influence on the ground surface temperature and the local circulation itself through the radiative process.

To summarize :

(1) The calculation of net atmospheric longwave radiation is indispensable to simulationg the surface inversion layer and thin mountain wind on the slope. A sufficient fall of the ground surface temperature facilitates these processes in connection with the atmospheric longwave radiation.

(2) The existence of clouds in the daytime suppresses the intensity of local circulation through radiative process, but on the other hand it clearly emphasizes the vertical velocity over the mountain through cumulus convection. Namely, the influence of both radiative and convective processes must be taken into consideration in numerical simulations including clouds.

No conclusion can be drawn, since we have only an insufficient number of experimental results. The effect of cumulus convection should not be computed separately in the simulation of local circulations because there is a possibility of numerical instability.

(3) Warming in the cloud layer, cooling in the upper part of it and the layer just above it can be simulated if we calculate both sides of cloud effect. The anti-slope wind becomes weak though the vertical velocity over the mountain is strengthened by clouds with these effects.

(4) If clouds remain after sunset, the depression of ground surface temperature is interrupted through the decrease of outgoing longwave radiative flux from the ground. This process delays the appearance of mountain

Acknowledgements: The author would like to express his gratitude for the continuing guidance and encouragement provided by Dr. Shoichi Arakawa. He also wishes to express his thanks to Mr. H. Kondo, Dr. F. Kimura and Mr. T. Kobayashi for valuable discussions and Miss Y.Miyauchi for typing the manuscript.

The numerical calculations were done with the use of HITAC M-200H of the Meteorological Research Institute.

Appendix : List of symbols and constants

$\mathrm{h}:$ depth of the model atmosphere

$u, v$ : east-west and north-south components of wind velocity

$w^{*}$ : vertical component of wind velocity measured by $z^{*}$-coordinate

$t$ : time 
$x, y$ : horizontal Cartesian coordinate

$z^{*}$ : vertical terrain following coordinate

$f$ : Coriolis parameter, $0.84 \times 10^{-4} \mathrm{sec}^{-1}$

$\Theta$ : reference potential temperature of the model atmosphere $(308.0 \mathrm{k})$

$\theta^{\prime}: \theta-\Theta$

$\theta:$ potential temperature

$\pi^{\prime}:$ deviation from the reference Exner's function

$\mathrm{g}:$ acceleration of gravity

$z_{T}$ : height of the Euler layer top $(4800 \mathrm{~m})$

$z_{G}:$ ground elevation

$K_{H}$ : horizontal exchange coefficient

$K_{m}, K_{\theta}, K_{r}$ : vertical diffusion coefficient of momentum, heat and mixing ratio

$r$ : mixing ratio

$r_{1}:$ mixing ratio at $z^{*}=25 \mathrm{~m}$

$\left(r_{s}\right)_{0}$ : saturated mixing ratio on the ground surface

$\beta$ : evaporation efficiency

$w^{\prime}$ : wetness of the soil

$\theta_{F}$ : potential temperature of the free atmosphere (322.6K)

$\tilde{h}_{m}$ : initial depth of the material layer $(1200 \mathrm{~m})$

$h_{m}:$ depth of the material layer

$F$ : empirical coefficient for suppressing the computational mode

$\Gamma$ : vertical potential temperature lapse rate

$\theta_{\text {sea }}:$ initial potential temperature at sea level

$\left(T_{g}\right)_{0}$ : average surface soil potential temperature

$T_{g}$ : surface soil potential temperature

$U:\left(u^{2}+v^{2}\right)^{1 / 2}$

$u_{\infty}^{*}$ : efective water vapor amount of a whole air column

\section{References}

Atkinson, B.W., 1981: Meso-scale Atmospheric Circulation, 251-279, Academic Press.

Bhumralker, C.M., 1975 : Numerical expriments on the computation of ground surface temperature in an atmospheric general circulation model. J. Appl. Meteor., 14, 1246-1258.

Blackadar, A. K. 1962 : The vertical distribution of wind and turbulent exchange in a neutral atmosphere. J. Geophys. Res., 67, 3095-3102.

Deardorff J.W., 1978 : Efficient prediction of ground surface temperature and moisture, with inclusion of a layer of vegitation. J. Geophys. Res., 83, 1889-1903.

Elsasser, W. M., 1942: Heat transfer by infrared radiation in the atmosphere. Harvard Meteorological Studies, No. 6, 107pp.

Katayama, A., 1972: A simplified scheme for computing the radiative transfers in the troposphere. Numerical Simulation of Weather and Climate. Technical Report, No. 6, Dept. of Meteorology, UCLA. , 1978: Kisho Kenkyu Note, 134, 153-200.

Kikuchi, y. S. Arakawa, F. Kimura, K. Shirasaki and Y. Nagano, 1981: Numerical study on the effects of mountains on the land and sea breeze circulation in the Kanto Districts. J. Met. Soc. Japan, 59, 723-283.

Kimura. F., 1983 : A numerical Simulation of local winds and photochemical airpollution (1): two -dimentional land and sea breeze. J. Met. Soc. Japan, 61, 862-878.

- 1984 : Observations and numerical experiments on localcirculation and medium-range transport of air pollutions. Tech. Rep. Meteorol. Res. Inst., No. 11 pp. 227-232 (in Japanese).

- and S. Arakawa, 1983: A numerical experiment on the nocturnal low level jet over the Kanto Klain. J. Met. Soc. Japan, 61, 848-861.

Kondo, J., O. Kanechika and N. Yasuda, 1978: Heat and momentum transports under strong stability in the atmospheric surface layer. J. Atmos. Sci., 35, 1012-1021.

Kurihara, Y. 1973: A scheme of moist convective adjustment. Non. Wea. Rev., 101, 147-553.

Liou, K. N., and G. D. Wittman', 1979: Parameterization of radiative properties of clouds. J. Atmos. Sci., 7, 1261-1273.

List, R. J., 1971: Smithonian Meteorological Tables, Smithsonian Institution Rress, Washington, D. D., 527 pp.

Magata, M., 1965: A study of the sea breeze by the numerical experiment. Pap. Met \& Geophy., 16, 23-37.

Manabe, S., and R. T. Weatherald, 1976: Thermal equilibrium of the atmosphere with a given distribution of relative humidity. J. Atmos. Sci., 24, 82-100.

Mellor, G. L., and T. Yamada, 1974 : A hierarchy of turbulent closure model for planetary boundary layers. J. Atmos. Sci., 31, 1791-1805.

Ookouchi, Y. and Y. Wakata, 1984: Numerical simulation for the topographical effect on the sea-land breeze in the Kyushu Island. J. Met. Soc. Japan, 61, 864-879.

Rodgers, C.D., 1967: The radiative heat budjet of 
the troposphere and lower stratosphere. Planetary Circulation Project, Dept. Met., MIT, Rep. No. 2, 99p.

, and C.D. Walshow, 1966: The computation of infrared cooling rate in planetary atmosphere.

Quart. J. Roy. Meteor. Soc., 92, 67-91.

Segal, M., Y. Mahrer and R. A. Pielke, 1982: Application of a numerical mesoscale model for the evaluation of seasonal persistent regional climatological patterns. J. Appl.
Meteor., 21, 1754-1762.

Wu, S.S., 1965: A study of heat transfer coefficients in the lowest 400 meters of the atmosphere. J. Geophys. Res., 70, 1801-1807.

Yamada, T., 1981: A numerical simulation of nocturnal drainage flow. J. Met. Soc. Japan, $\mathbf{5 9}$, 108-122.

Yamamoto, G., 1952: On a radiation chart. Sci. Rept. Tohoku Univ., Ser. 5, Geophysics, 4, 9-23.

雲の影響を考慮した局地循環に関する数値実験的研究

\footnotetext{
白 崎 航 一

二次元数値モデルを用いて，局地循環に及ぼす，雲（積雲）と放射の影響を調べた。モデルには山と海面が含 まれている。

数値実験は以下の四つのケースを比較する形で行う。ケース 1 はいわば基本モデルであり，地表面温度を予報 するために, ネットの放射フラックスを地表面で計算する。しかし, 大気中での放射による加熱, 冷却, そして 雲の影響は考慮に入れていない。ケース 2 は, 地球表面を含む大気各層において放射のネットクラックスを計算 するが，積雲対流過程は含まれていない。ケース 3 は，ケース 1 と同じであるが，積雲対流過程が含まれている。 最後にケース 4 は, ケース 2 にさらに，積雲対流，及びその放射過程への影響が評価できるモデルである。

この四つのケースを用いて計算した結果，雲による，地表面温度及び局地循環への影響がかなり大きいことが 示された。

夜間斜面に形成される，接地逆転層や，地表ごくうすい層で生じる山風を再現させるためには，大気中の各層 でネットの長波長放射を見積る必要があること。日中山頂上空に積雲が形成される場合, 積雲対流により上昇流 は, 当然強化されるが, 地表面に入射する太陽放射の急速な減少から，循環全体としてはむしろ押えられること。 つまり雲は循環に対して，相反する効果を合わせもつこと等が示された。又積雲対流とその放射への影響を見積 るケースでは, 雲層の気温は周囲より高く, 逆に雲層のごく上部, 及び雲頂直上の気温は低くなる結果が得られ た。さらに, 日没後上空に雲が残っていると, 結果的に雲は山風の出現をおくらせる役割を果していることも明 らかになった。
} 